\title{
La Traza Oculta de la Plaza de Toros de la Real Maestranza de Caballería de Sevilla. Sobre la Geometría de su Planta
}

\section{The Hidden Layout of the Real Maestranza de Caballería de Sevilla Bullring. About its geometry}

J. A. Carbajal ${ }^{(*)}, \underline{\text { R. Carbajal }}^{(*)}$, N. Carbajal ${ }^{(*)}$

RESUMEN

Quizás una de las características más llamativas de la Plaza de la Real Maestranza de Caballería de Sevilla sea la singularidad de su traza, la irregularidad de su ruedo. Una forma insólita a la que no se ha encontrado justificación convincente. No existen documentos que la expliquen en los archivos de la Corporación y tampoco puede dudarse de la solvencia y destreza de los maestros mayores, ingenieros militares y arquitectos que a lo largo de ciento veinte años la levantaron. Ahora, creemos haber encontrado una explicación a esa geometría irregular. Un razonamiento basado en la historia de su construcción, también en la observación tanto de la planimetría histórica conservada como de los nuevos levantamientos, y sobre todo en el conocimiento que nos han proporcionado del edificio las obras de reforma y conservación llevadas a cabo en ella durante estos últimos años.

Palabras clave: Plaza de Toros, Maestranza, Sevilla, Trazado Geométrico.

\section{ABSTRACT}

Perhaps one of the most showy characteristics of the Bullring of the Real Maestranza de Caballeria of Seville is the singularity of its geometric layout, the irregularity of its arena. An unusual form to which no convincing justification has been found. There are no documents that explain it in the archives of the Corporation and there is no doubt about the solvency and dexterity of the major teachers, military engineers and architects who built it over a hundred and twenty years. Now, we think we have found an explanation for this irregular geometry. A reasoning based on the history of it construction, also in the observation of the historical and new planimetry, and especially in the knowledge that has provided us with the building of the works of reform and conservation carried out In it during these last years.

Keywords: Bullring, Maestranza, Seville, Geometric Layout.

(*) Universidad de Sevilla (España).

Persona de contacto/Corresponding author: rcarbajal@us.es (R.Carbajal)

ORCID: http://orcid.org/oooo-0oo2-2126-2240 (J. A. Carbajal); http://orcid.org/oooo-0oo2-0506-2150 (R. Carbajal); http://orcid.org/oooo-0002-0423-2605 (N. Carbajal)

Cómo citar este artículo/Citation: Carbajal, J. A., Carbajal, R., Carbajal, N. (2018). La Traza Oculta de la Plaza de Toros de la Real Maestranza de Caballería de Sevilla. Sobre la Geometría de su Planta. Informes de la Construcción, 70(549): e246. https://doi. org/10.3989/id.55344.

Copyright: (c) 2018 CSIC. Este es un artículo de acceso abierto distribuido bajo los términos de la licencia de uso y distribución Creative Commons Reconocimiento 4.0 Internacional (CC BY 4.0). 
Quizás una de las características más llamativas de la Plaza de la Real Maestranza de Caballería de Sevilla sea la singularidad de su traza, la irregularidad de su ruedo, no es circular, tampoco ovalado y sí, en apariencia, más próximo a un ovoide deformado. Una forma insólita a la que no se ha encontrado justificación. No existen documentos que la expliquen en los archivos de la Corporación y tampoco puede dudarse de la solvencia y destreza de los maestros mayores, ingenieros militares y arquitectos que a lo largo de ciento veinte años la levantaron, de ahí que en ámbitos muy diversos de la ciudad hayan surgido múltiples especulaciones al respecto, que por lo general giran en torno a acontecimientos que pudieron afectar a las dimensiones del terreno disponible, una superficie finalmente presionada por el caserío circundante en parte levantado al tiempo que la plaza (Figura 1); conjeturas no del todo descartables pero que por sí solas no resultan convincentes, pues su traza final no puede ser fruto tan sólo de circunstancias accidentales y ajenas a la propia plaza, sino que tras su lograda terminación ha de subyacer una geometría intencionada.

Ahora, creemos haber encontrado esa geometría subyacente. Se trata de un razonamiento basado en los estudios y escritos sobre la Plaza de diversos historiadores interesados en su construcción, también en la observación tanto de la planimetría histórica conservada como de los nuevos levantamientos, y sobre todo en el conocimiento que nos han proporcionado del edificio las obras de reforma y conservación llevadas a cabo en ella durante estos últimos años.

\section{EL ASENTAMIENTO SOBRE EL ARENAL. LAS PLAZAS DE MADERA}

Es sabido que la Real Maestranza de Caballería ocupó el Arenal una vez le fue concedido por el Rey Felipe V el privilegio de construir una plaza para celebrar Fiestas de Toros, y también es conocido cómo antes de iniciar las obras de fábrica levantaría en él hasta cuatro plazas de madera, la primera (1730) entre el Convento del Pópulo y el Monte del Baratillo de planta rectangular como réplica de la de San Francisco -donde con anterioridad se habían venido celebrando estos festejos-y las otras tres (1733, 1739-40 y 1759) «ochavadas» o poligonales próximas al círculo construidas sobre el propio monte una vez allanada su superficie. Entendiéndose por «ochava» cada uno de los lados del polígono que cerraba la plaza con independencia de su número. A este respecto Fátima Halcón hablando de la segunda de las plazas (1733) escribe: «La figura que se le dio a esta segunda plaza fue un círculo en la parte interior mientras que en la exterior presentaba una estructura ochavada [...] especificándose que debía tener un balcón de mayor proporción y belleza llamado, «Balcón del Srmo. Infante» » (1)

Otros autores apuntan como origen de esta circularidad del ruedo, al Toril de Tablada, una edificación situada en la vega del mismo nombre, de forma circular y labrada en ladrillo, a la que al final del s. XVII acudían los nobles sevillanos a correr y acosar a los toros. Una acuarela del mismo, firmada por Luis Jiménez Aranda (1908), se conserva en el Museo Taurino de la Plaza con leyenda en este sentido.

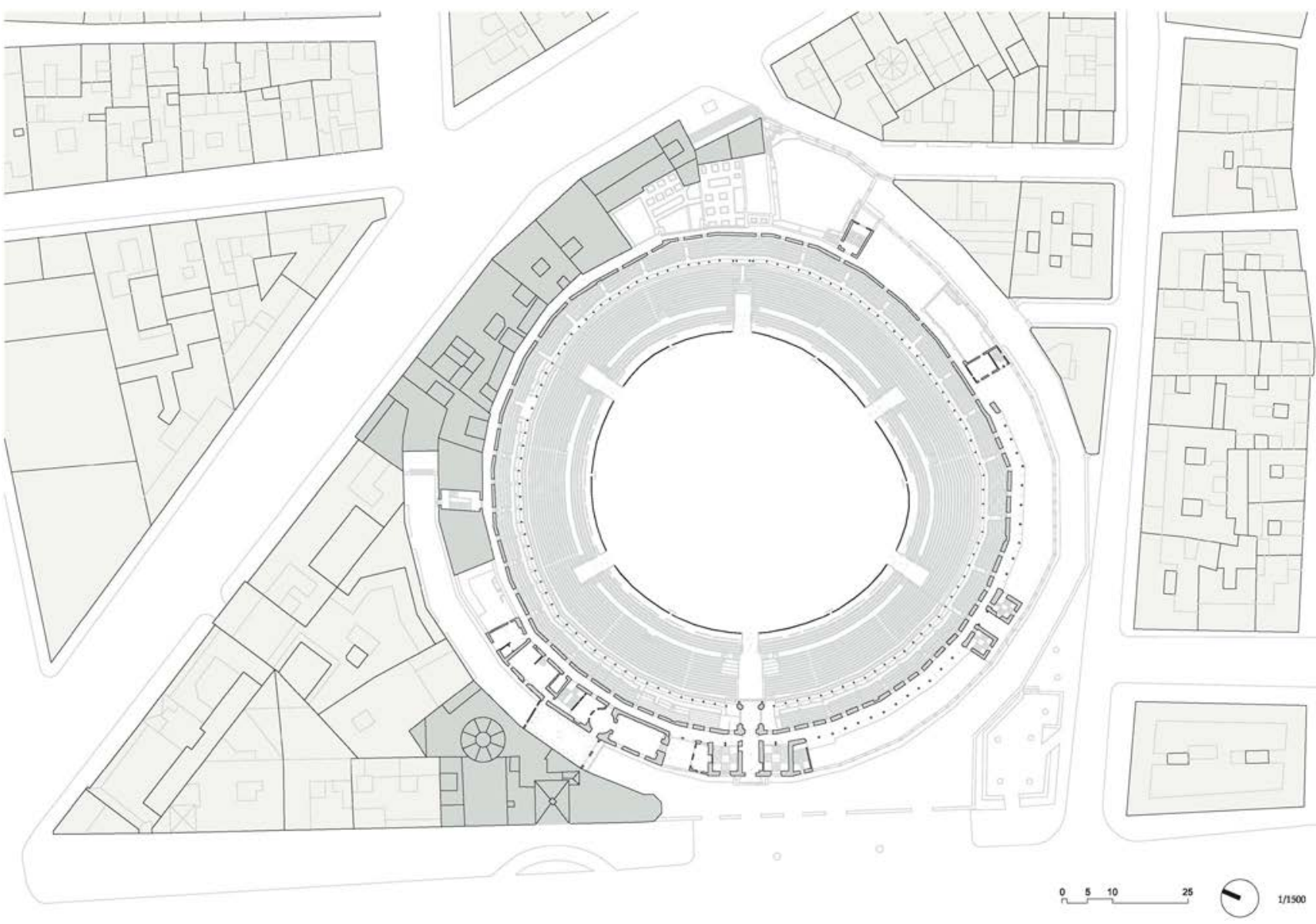

Figura 1. Planta Alta Estado Actual Plaza de Toros de la Real Maestranza de caballería de Sevilla. Escala 1/50o. (Dibujo de los autores) 
En todas ellas se mantuvo el eje ritual, eje simbólico del festejo, Balcón del Sr. Infante (Puerta del Príncipe) - Balcón de los Caballeros Diputados (Puerta de Toriles), y al menos en la última de estas plazas otras cuatro puertas dieron acceso al ruedo, «Sabemos que debía estar compuesta por 110 balcones y 101 andamiadas entre las que había al menos cuatro puertas; la primera entre las andamiadas 14 y 15, era la de la salida de los toros muertos; por la segunda, entre los números 41 y 42, entraba la tropa -es de suponer que para el despejo del público que ocupaba el ruedo para posteriormente acceder a sus asientos-; la tercera, entre las andamiadas 68 y 69, era la de los picadores; y la cuarta, entre las 87 y 88 , podría ser la del encierro. El toril estaba ubicado entre las andamiadas número 54 y $55 \ldots »(2)$

Considerando que, tanto al balcón del Sr. Infante como al de los Caballeros Diputados, singularizados por su mayor proporción, le corresponderían un frente equivalente a dos balcones, podemos suponer que la plaza dispondría de veintiocho ochavas, a razón de cuatro balcones por ochava. Sabemos además, por Fátima Halcón (3), que el diámetro de la barrera de esta plaza era de 82 varas castellanas (equivalentes a 68,54 m) (Figura 2).

\section{LA OBRA DE FÁBRICA. $1^{\text {a }}$ FASE. 1761-1762}

La obra de fábrica se iniciaría en 1761 durante la Tenencia del Marqués de Carrión. En ese año «la Junta de Gobierno tomó el acuerdo de encargar un proyecto a Francisco Sánchez de Aragón, Maestro Mayor de la Audiencia, manifestando que lo llevara a cabo en un «mapa completo», es decir, un plano general de la plaza y además, que se detallara tanto la obra interior como la exterior. La forma de la plaza debía seguir las trazas de la anterior de madera. Su figura circular estaría inscrita en otra poligonal, de modo que se iría construyendo en ochavas, siendo cada una equivalente a cuatro arcos.» (3).

La ochava o sector de plaza habría de comprender, la parte proporcional de tendido, un almacén ampliado bajo él, las bóvedas de cubrición del mismo y sobre ellas los arcos

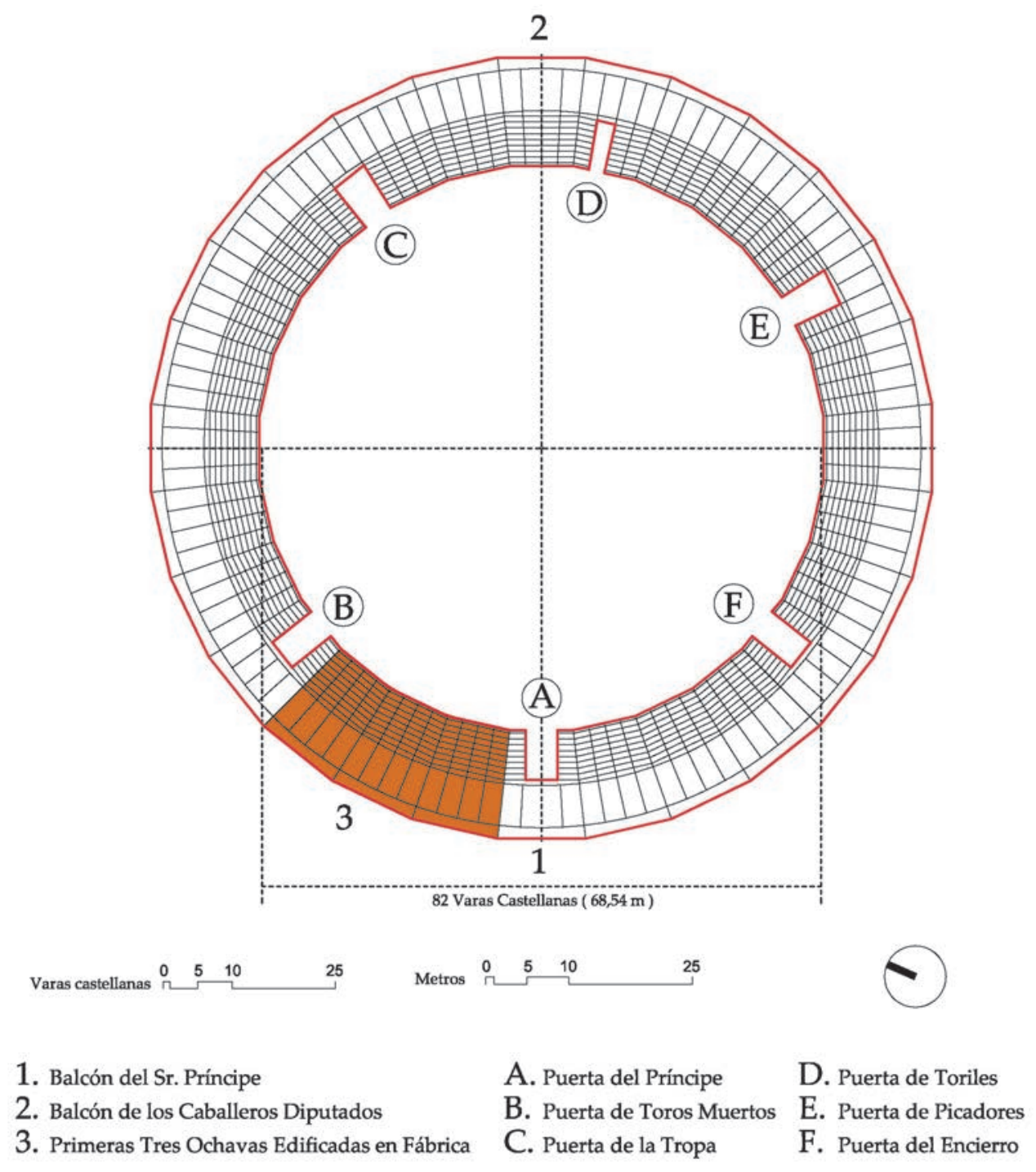

Nota aclaratoria: El esquema refleja literalmente la descripción de los historiadores y de haber sido todas las andamiadas de igual dimensión, la Puerta de Toriles no coincidiría exactamente con la parte baja del Balcón de los Caballeros Diputados.

Figura 2. Esquema de la última Plaza de Madera. (Dibujo de los autores) 
o balcones de la arquería en número de cuatro y, rodeando al exterior esta arquería, viviendas. Así se construyeron en esta primera fase "tres ochavas, con doce balcones y «andamios»(tendidos), dando al ruedo; y al exterior, tres almacenes y tres viviendas encima.». La historiadora $\mathrm{M}^{\mathrm{a}}$ del Valle Gómez de Terreros las sitúa entre los arcos impares 11 al 33, ambos inclusive. (4)

Iniciaría su levantamiento el propio Sánchez de Aragón y lo finalizaría Pedro de San Martín, Maestro Mayor de la ciudad (Figura 3).

\section{LA OBRA DE FÁBRICA. 2a FASE. 1763-1766}

En el Libro de Cuentas Generales de la Real Maestranza (1748-1790) figura el pago el 29 de Julio de 1761 (ordenado por el Marqués de Carrión a pocos meses de iniciar las obras) realizado al ingeniero que hizo los diseños de la plaza para enviarlos al Sr. Infante Duque de Parma y Hermano Mayor de la Maestranza para su aprobación, y así mismo los costes de dicho envío a Italia en un cañón de plata al que acompañaba el siguiente escrito:

«La Maestranza de Caballería hace presente a V.A.S ${ }^{\mathrm{a}}$. como tiene determinado fabricar de material el anfiteatro, o circo donde se lidian los toros en las fiestas que por R. privilegio ejecuta anualmente para evitar los graves inconvenientes a que está expuesto el que hoy conserva de madera, logrando por este medio excusar el costoso reparo que todos los años necesita pues las lluvias del invierno, y los rigurosos calores del verano inutilizan mucha parte de sus maderas fabricando a un mismo tiempo algunas fincas que pueden contribuir en parte a los gastos que se ofrecen en el diario del año. Y aunque esta obra está principiada en lo exterior, se suspendió hasta tanto que se pudiese construir en su todo para que vaya ceñida a las reglas de arquitectura; y estando resuelta

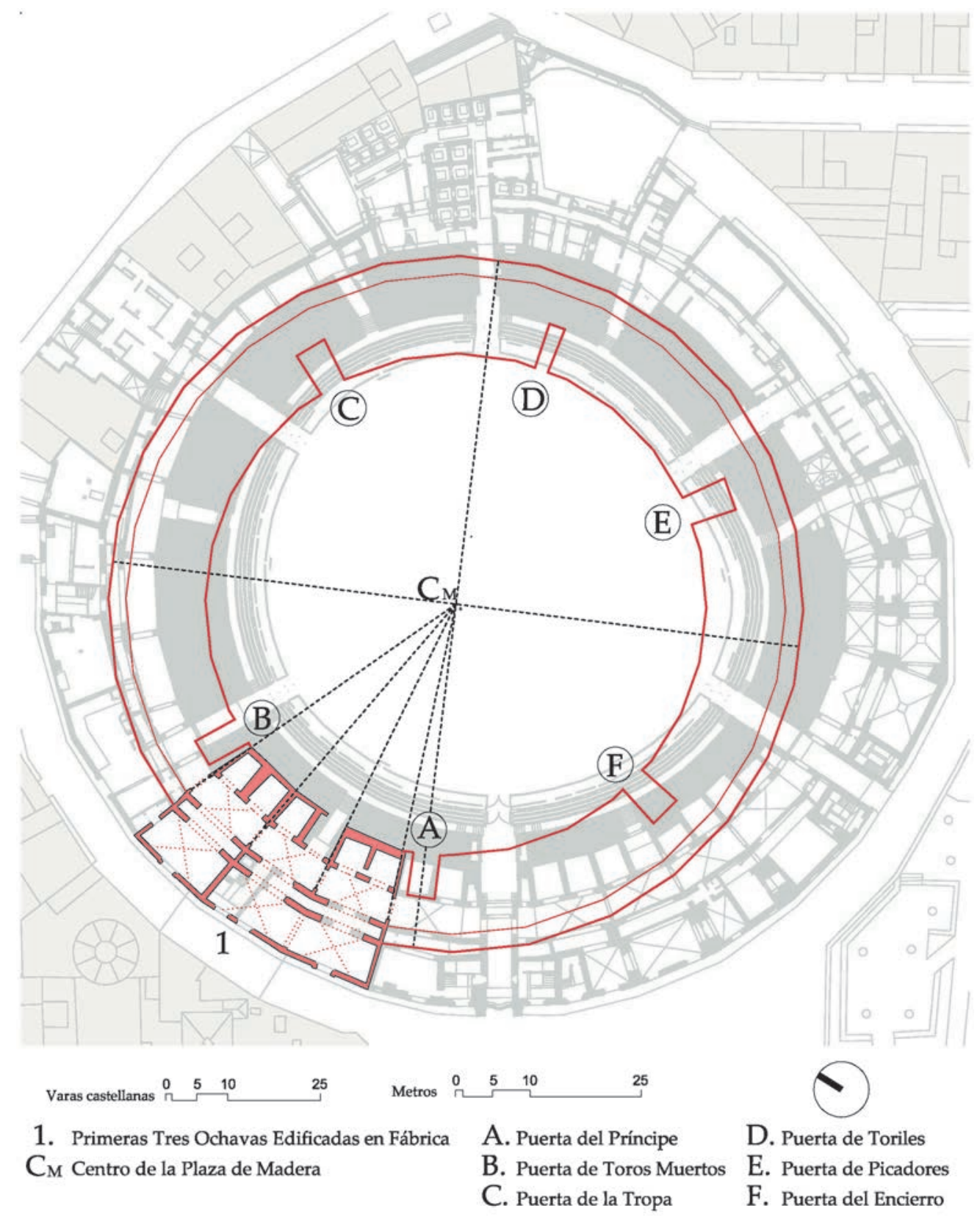

Figura 3. $1^{\mathrm{a}}$ Fase de la Obra de Fábrica. 1761-1762. (Dibujo de los autores) 
su continuación remite a V.A.S . los diseños para que siendo del gusto de V.A.S . y de su Real agrado el que continúe esta obra, tenga la Maestranza la satisfacción de que la ejecuta con su real orden a la que siempre estará obediente [...]» (5).

Pareciera que tras la calificación de «obra ceñida a las reglas de arquitectura» subyaciera una sensibilidad ilustrada, un gusto por la racionalidad y el clasicismo, y ello lo refuerza el hecho de recurrir a un ingeniero militar para la elaboración de sus diseños.

Fue en Febrero de 1763, estando al frente de la Maestranza el Marqués de las Torres, cuando se recibió la aprobación Real de la «idea y el diseño que se proponían para la construcción de la Plaza de Toros», siendo leída dicha notificación en Junta celebrada el día 27 del mismo mes. En ella se mostraron los diseños de la portada y Balcón del Príncipe, y el de la obra exterior sin llegar a especificar el autor o autores del mismo. Según se explicó la variación del exterior se reducía a una galería cubierta construida en el piso principal, sobre los almacenes, eliminando la edificación de casas en esa parte superior (5). Dicho de otra forma, esta variación consistiría en la construcción de una galería cubierta antecedida de unas amplias terrazas que dieran acceso a los balcones o tendidos altos, y que son ambas, arquería y terrazas, las que hoy conforman la singular y atractiva fachada de la Plaza sobre el Paseo de Colón.
¿Quién fue el ingeniero que introdujo esas modificaciones sustanciales al diseño de Sánchez de Aragón? En este punto Gómez de Terreros se inclina por la autoría de Sebastián Van der Bocht, ingeniero militar español nacido en Bruselas, y que por entonces trabajaba en Sevilla en la terminación de la Real Fábrica de Tabacos, y al que también relaciona con la construcción de la Portada y Palco del Príncipe, coronado por un frontón partido en el que destacan las alegorías del Po y el Guadalquivir (Parma y el Po, Sevilla y el Guadalquivir). Sin embargo, Pedro Romero de Solís (6), habla de la probable participación o asesoramiento de Roque Joaquín de Alcubierre, ingeniero de zapadores aragonés, y que destinado en Sevilla formó parte del estado mayor del Conde de Montemar (miembro de la Junta de Gobierno de la Real Maestranza) en la Guerra de Nápoles. Personaje muy interesado por la arqueología, que realizó excavaciones en el teatro de Erculano y posteriormente en Pompeya y su anfiteatro (1748-1750) (Figura 4), en una campaña que se desarrolló entre los años 1738-1780. Romero de Solís, en lo que puede entenderse una brillante intuición, encuentra una acertada analogía entre el ambulacro del Anfiteatro de Pompeya que da acceso a las localidades altas y las terrazas referidas que lo hacen a los balcones o tendidos altos de la Plaza de Toros de la Real Maestranza.

También según Gómez de Terreros se construyeron seis ochavas y media en esta segunda fase bajo la dirección de

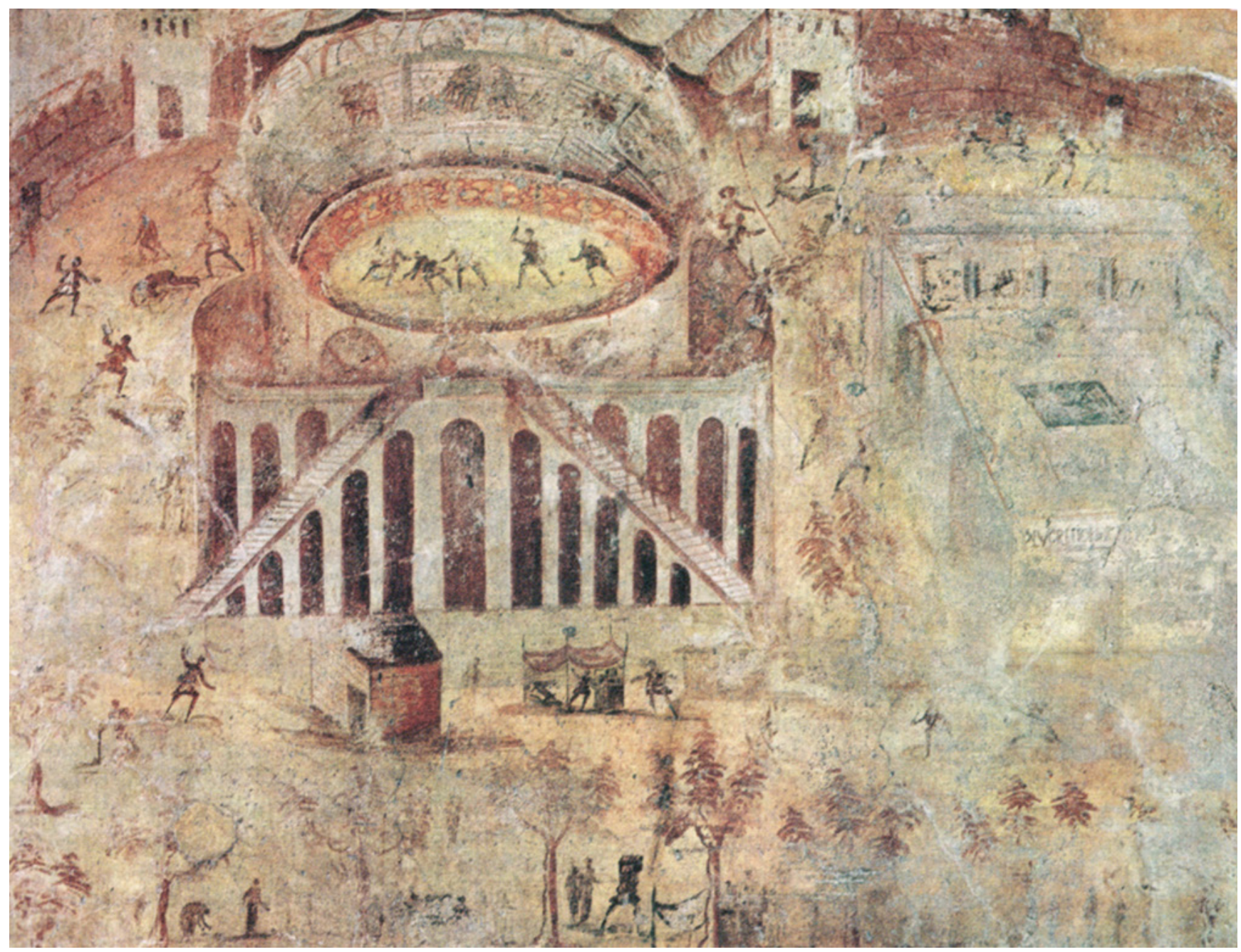

Figura 4. Imagen del fresco titulado «Risa nell anfiteatro Pompeiani e Nucerini» Procedente de Pompeya y fechado en la Segunda mitad del s.I aC. Conservado en el Museo Arqueológico Nacional de Nápoles. Inventario 112222. 
Pedro de San Martín y teniendo como colaborador a su hijo Vicente. Así mismo se terminó el Balcón del Príncipe con su frontispicio y coronación, y al tiempo se habían conformado simétricamente en antepechos, cornisas, barandas de balcones y gradas altas de mampostería las tres ochavas de la fase anterior. Por el exterior, se dieron por concluidos el primer cuerpo de la portada principal y los arranques del segundo, sus dos escaleras y las torres colaterales, todo el corredor y azoteas de balcones de Maestranza y los de la Real Justicia, Señores Asistentes y Regentes, más la mitad de la puerta del costado derecho, que debía ser la del Encierro, con la torre escalera adjunta.

Para ser exactos, según hemos podido comprobar a través de las obras de conservación realizadas, se construyeron seis ochavas y un cuarto de la adyacente, cuarto efectivamente coincidente con una de las torres-escalera que flanquean la Puerta del Encierro, escalera de sombra (actual Puerta $\left.n^{0} 8\right)$.
Esas nueve ochavas y un cuarto (Figura 5), hasta aquel momento levantadas, vienen a mostrar el modelo a seguir en la construcción de la plaza. Tendidos, arcos o balcones, galería exterior y terrazas, almacenes bajo ellas, puertas y torres-escalera de acceso al piso alto flanqueándolas, quedan en ellas definidas como elementos a repetir.

No está claro sin embargo, si pertenecieron al plano de una plaza circular u ovalada, y a su vez de treinta o veintiocho ochavas. Si podemos decir que de pertenecer a una plaza circular, el diámetro de su ruedo hubiera alcanzado las cien varas castellanas $(83,5 \mathrm{~m})$, dimensión excesiva para la lidia y toreo de a pie que se imponía por aquellos años.

\section{EL PLANO DE VICENTE DE SAN MARTÍN-SIMANCAS}

A partir de 1766 se suspenderían las obras de construcción de la plaza permaneciendo paradas hasta 1781 , y es en este pe-

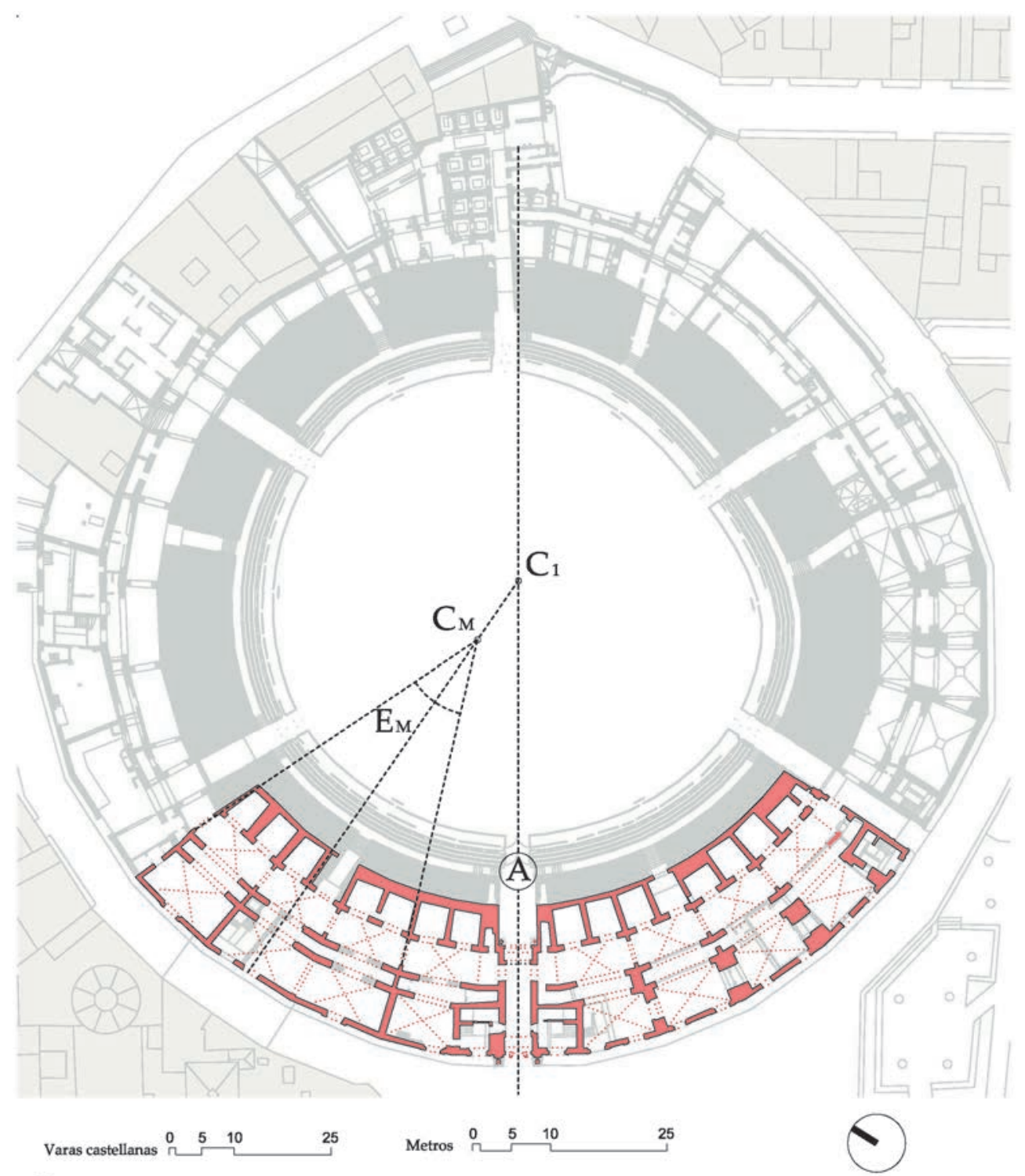

$\mathrm{C}_{\mathrm{M}}$ Centro de la Plaza de Madera

A. Puerta del Príncipe

$\mathrm{C}_{1}$ Centro de las Nuevas Ochavas

$E_{M}$ Eje Bisectriz de las Tres Ochavas Edificadas en la Primera Fase

Figura 5. $2^{\text {a }}$ Fase de la Obra de Fábrica. 1763-1766. (Dibujo de los autores) 
ríodo en el que Vicente de San Martín, por entonces Maestro Mayor de la Ciudad y de la Real Maestranza, probablemente elabora el conocido plano de la plaza que se conserva en el Archivo de Simancas. Por los escritos y documentación que lo acompañaban podría datarse entre los años 1766 y 1771, es decir, entre la fecha en que se produce una primera solicitud del Marqués de las Torres al Rey Carlos III (29 de Enero de 1766) expresando el deseo de la Corporación de que fuera aumentado el número de corridas correspondientes al antiguo privilegio, con el objeto de reunir los medios económicos con los que continuar las obras; y otra muy similar, remitida el 19 de Mayo de 1771 enviando un "plan adjunto" que mostraba el estado de las obras. Este plan adjunto pudo ser el que ahora se conserva en Simancas ya que en él se hace distinción entre las ochavas ya construidas y las que restan por levantar. Tras ser denegadas ambas solicitudes las obras continuarían paralizadas hasta su reanudación en 1781. (7)

El plano representa una plaza de veintiocho ochavas que no es exactamente circular ni tampoco ovalada, podríamos de- cir que es una figura geométricamente no clasificable. En la leyenda que lo acompaña se precisa que «las nueve ochavas que manifiesta el plano que sus diámetros son en puntos encarnados están concluidas como manifiesta el alzado»; las diecinueve restantes que la cierran estarían por tanto sin terminar. En él de nuevo se recoge el eje ritual del festejo «Balcón del Sr. Infante (Puerta del Príncipe) - Balcón de los Caballeros Diputados (Puerta de Toriles)» al que nos hemos referido con anterioridad, y otras cuatro puertas, regularmente dispuestas y flanqueadas por torres-escalera que alcanzan el piso alto, marcan dos nuevos ejes virtuales, uno Puerta de Picadores (Cuadrillas) - Puerta de Toros Muertos (Arrastre) y el otro, Puerta de la Tropa (Despejo) - Puerta del Encierro, este último de división entre sol y sombra (Figura 6).

Los anillos poligonales concéntricos, en su plano inferior y de interior a exterior corresponden: el primero a las bóvedas existentes bajo los tendidos y el segundo, tercero y cuarto a los almacenes que, en la proximidad a la Puerta de Toriles,

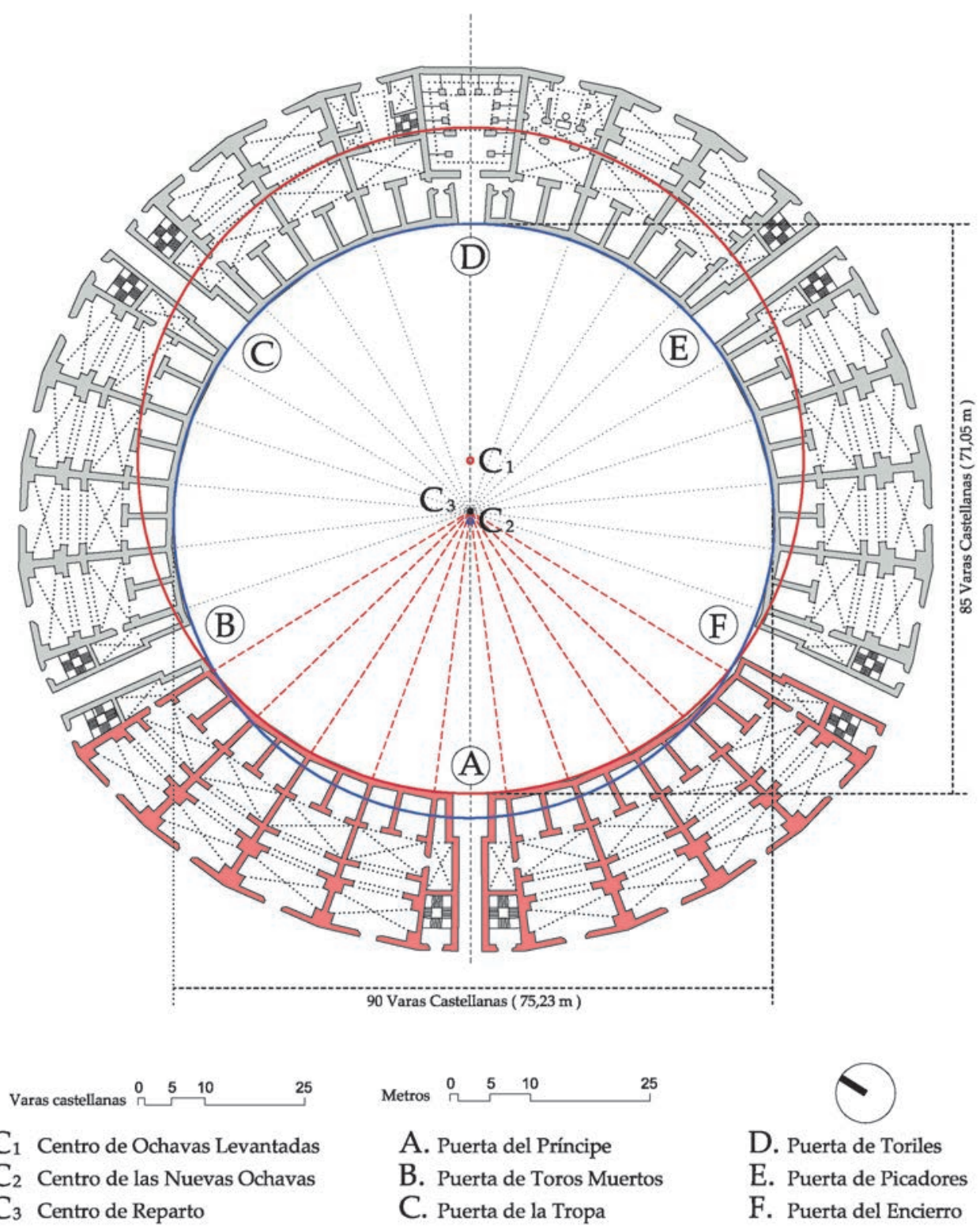

Figura 6. Plano de Simancas Redibujado. (Dibujo de los autores) 
son sustituidos por los chiqueros, las caballerizas y las estancias de los Diputados; y en el plano superior: el segundo anillo corresponde a los balcones, el tercero a la galería exterior y el cuarto a las terrazas.

Geométricamente como decíamos se trata de una traza inusual, en la que San Martín se limita a desplazar hacia la Puerta del Príncipe el nuevo centro de las diecinueve ochavas sin levantar, y superponer así un círculo de radio más pequeño al arco que describen las ochavas ya construidas. Ambos centros, antiguo $\left(\mathrm{C}_{1}\right)$ y nuevo $\left(\mathrm{C}_{2}\right)$, no aparecen grafiados en el plano, y sí un tercero $\left(\mathrm{C}_{3}\right)$, intermedio, desde el que se ordena el reparto de ochavas. Pareciera que con esta operación se hubiera pretendido bien reducir el ruedo de una planta circular de treinta ochavas, o bien transformar una planta ovalada en otra próxima a la circular, es decir volver a las plantas circulares de las plazas de madera que le precedieron.

El hecho es que este plano no parece haber contribuido a la traza actual de la plaza y que su finalidad no fuera otra que la de acompañar a la solicitud comentada reflejando el estado en el que se encontraban las obras.

Sí pudo tener cierta repercusión en la disposición y número de puertas y torres-escalera, en la formalización de las ochavas o en los propios alzados de la plaza, si bien todas estas cuestiones quedaron suficientemente definidas en la fase anterior.

\section{LA TERCERA FASE. 1781-1785. EL PLANO DESAPARECIDO}

Se construyeron en esta fase los tres cuartos que faltaban de la décima ochava, es decir la Puerta del Encierro y su segunda torre-escalera, y tres nuevas de sol. Ello queda acreditado en el plano posterior de Gaspar de San Martín (Figura 7). Un plano con planta esquemática y absolutamente circular fechado en 1793 y que se expone en el Museo de la Plaza; en él se especifica cómo «toda la parte del circulo que va encarnado es lo de piedra y lo de verde de madera», siendo trece las ochavas de piedra ya construidas.

De nuevo $\mathrm{M}^{\mathrm{a}}$ del Valle Gómez de Terreros nos habla de cómo a Vicente de San Martín se le encargó el levantamiento de un plano antes del inicio de esta fase (8) y más adelante confirma, refiriéndose también a ella: «Entre los pagos efectuados por la Corporación en estos años hay algunos de un interés especial. Destacan los efectuados al maestro Vicente de San Martín: uno de 350 reales por el trabajo de haber alzado el plano de la plaza de toros (30 de Julio de 1781) y otro de 120 reales como maestro de la obra por vía de gratificación.» (9)

¿Cómo fue este plano desaparecido? Hemos intentado restituirlo (Figura 8) tratando de encontrar una figura geométrica que respondiera tanto al arco que describen las ochavas de las dos fases anteriores como a la aparente deformación del

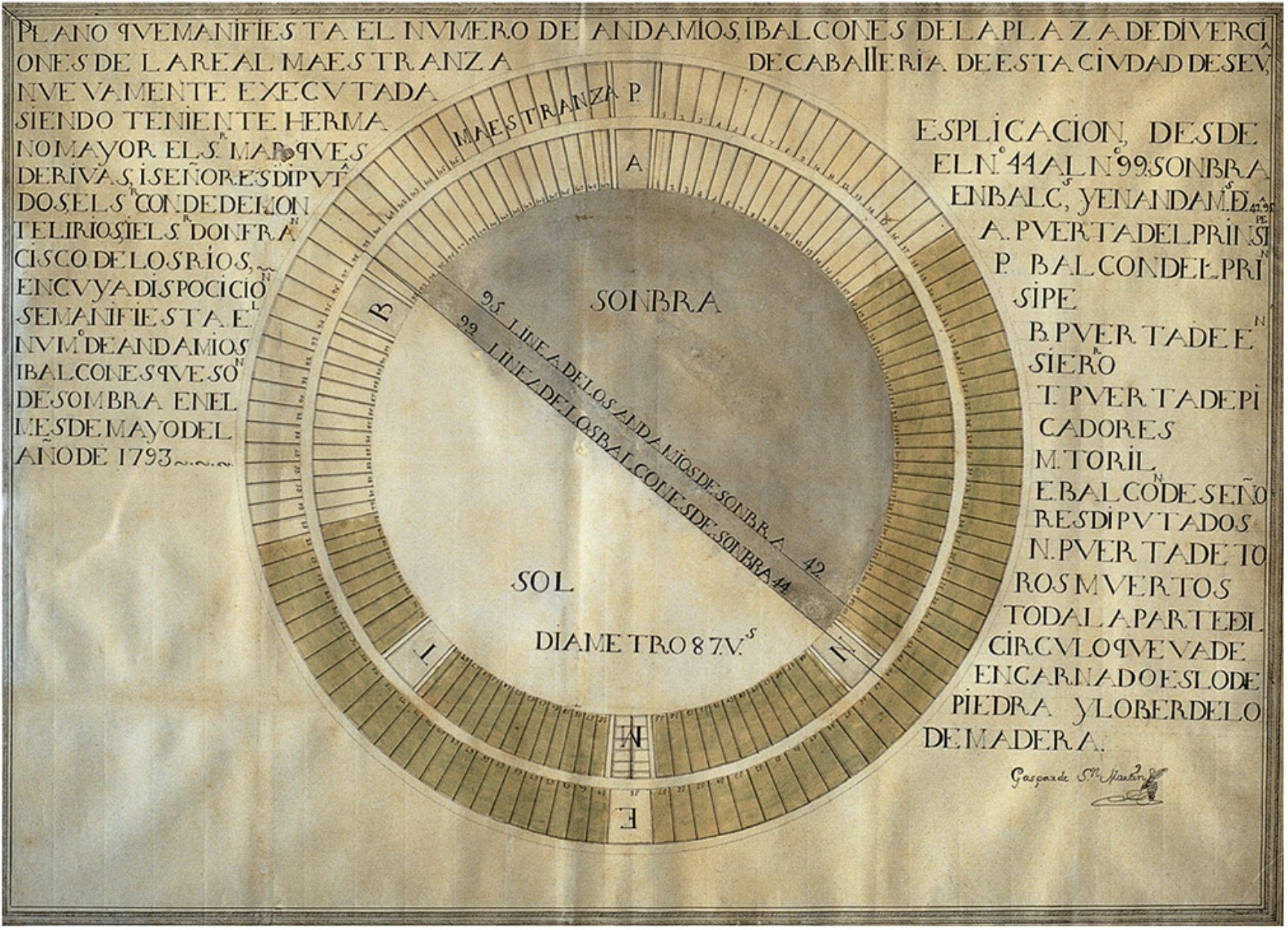

Figura 7. Plano de Vicente de San Martín. 1793. Conservado en el Museo de la Plaza. 


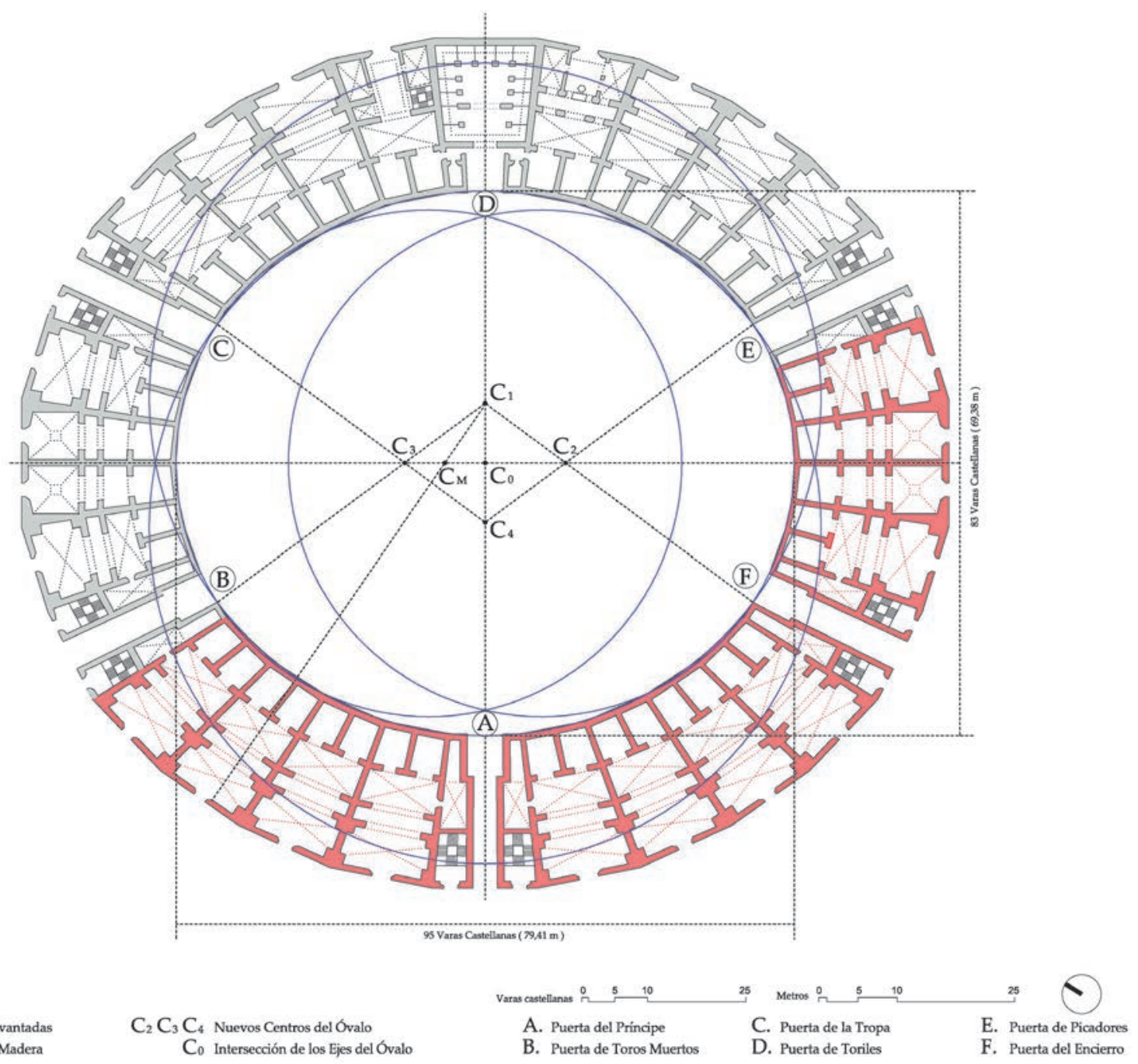

Figura 8. Hipótesis del Plano Desaparecido. En rojo las trece ochavas de fábrica. (Dibujo de los autores)

círculo que introduce Vicente de San Martín con el trazado de estas últimas y que en nada coincide con el plano de Simáncas.

Dicho de otro modo, hemos recreado el plano que respondiera a la planta de las trece ochavas construidas hasta el momento y el resultado ha sido el de un óvalo ortodoxamente trazado que coincide fielmente con ellas. Es decir, Vicente de San Martín, con el levantamiento de estas nuevas ochavas, viene a dar continuidad a la construcción de una plaza ovalada.

Con ello creemos resolver la duda planteada anteriormente en cuanto a si lo construido en las fases anteriores (Puerta del Príncipe incluida) respondiera a una plaza circular u ovalada. Todo parecía indicar que lo hacían a una ovalada, el término «anfiteatro» en lugar del de "plaza» empleado en el escrito de remisión de los primeros planos a Parma, el conocimiento de las excavaciones de Pompeya, la proximidad de Itálica y el gusto imperante por el clasicismo y la racionalidad, pero el levantamiento de estas últimas ochavas lo corrobora.

La restitución de este plano, hasta ahora desconocido se ha completado siguiendo las directrices que se deducen del Plano de Simáncas: número y disposición de puertas y torres de escalera de acceso al piso alto, formalización de ochavas y posición de chiqueros, caballerizas y estancias de los Caballeros Diputados.

\section{EL CERRAMIENTO DEL RUEDO. 1845-1849}

Entre los años 1785 y 1845, un intervalo de sesenta años, las obras permanecerían paradas, habiendo de convivir la obra de fábrica con los andamios de madera que, en un principio, esbozara Gaspar de San Martín. Por entonces ya habían sido levantadas entre otras plazas las de: Madrid de la Puerta de Alcalá (1754), la del Campo del Triunfo de Granada (1768), la de Ronda (1785) o Aranjuez (1830), todas ellas de planta circular; y elaborados proyectos sobresalientes de plazas también circulares, como los de Juan Bautista de la Corte para Valencia (1800) o el de Nagusía para Pamplona (1830), podría decirse que la definición del «tipo» estaba consolidada, de forma que cuando Juan Manuel Caballero y Ortiz, primer Arquitecto de la Plaza, académico y profesor de matemáticas, recibió en 1845 el encargo de reanudar las obras con el levantamiento de los tendidos y almacenes que restaban para cerrar el ruedo, hubo de recibirlo con las instrucciones de que éste resultara tan circular como las fábricas ya construidas (plaza, dependencias auxiliares y caserío que en su frente a la ciudad empezaba a envolverla) lo permitieran. 
Con esta orden se abandonaría la idea ilustrada de avanzar por ochavas. Primero se cerrará el ruedo, después se construirán, para apoyo de balcones, nuevos almacenes, también chiqueros y cuadras y finalmente se cerrará la arquería. Se respetará la posición sobre el tendido de las embocaduras de las puertas aún por construir, pero las escaleras exteriores de acceso al piso alto dejarán de flanquearlas, perdiendo su situación canónica respecto a ellas y surgiendo en adelante en aquellos puntos en los que resultaran más eficaces. Así mismo se interrumpirá la construcción de la galería alta exterior.

El cierre definitivo del ruedo, con el levantamiento de los nuevos tendidos, se produciría, tras varias fases de obra en las que fueron desmontándose los andamios de madera y reedificándolos de fábrica, en el año 1849. Juan Manuel Caballero lo cerró uniendo los extremos de las ochavas hasta ahora levantadas mediante el enlace consecutivo de arcos de circunferencia, dando así forma definitiva tanto al ruedo como a la Plaza, es decir consolidó la traza actual de la Plaza.
En este punto no es posible asegurar si Caballero se limitó a reafirmar el trazado de los tendidos de madera existentes (pues cómo decíamos habían convivido con la obra de fábrica sesenta años) o lo corrigió, sí que su éxito radicó en el hecho de que sentado en sus tendidos la Plaza se percibe circular. De haber continuado con el levantamiento de la plaza ovalada, ruedo y plaza, hubieran podido ser perfectamente regulares, sin recibir presiones del caserío (Figura 9).

Como es sabido Juan Talavera de la Vega, tras haber levantado el Balcón de Diputados entre los años 1867 y 1868, culminaría el cierre de la arquería y con ello la terminación de la plaza en el año 1881 (Figura 10).

\section{LA TRAZA OCULTA}

Las obras de reforma y conservación realizadas en los últimos años han permitido comprobar la exactitud de los datos aportados por la historiadora $\mathrm{M}^{\mathrm{a}}$ del Valle Gómez de Terreros en la definición espacial de cada una de las fases de obra, así como la elaboración de una planimetría, suficientemente

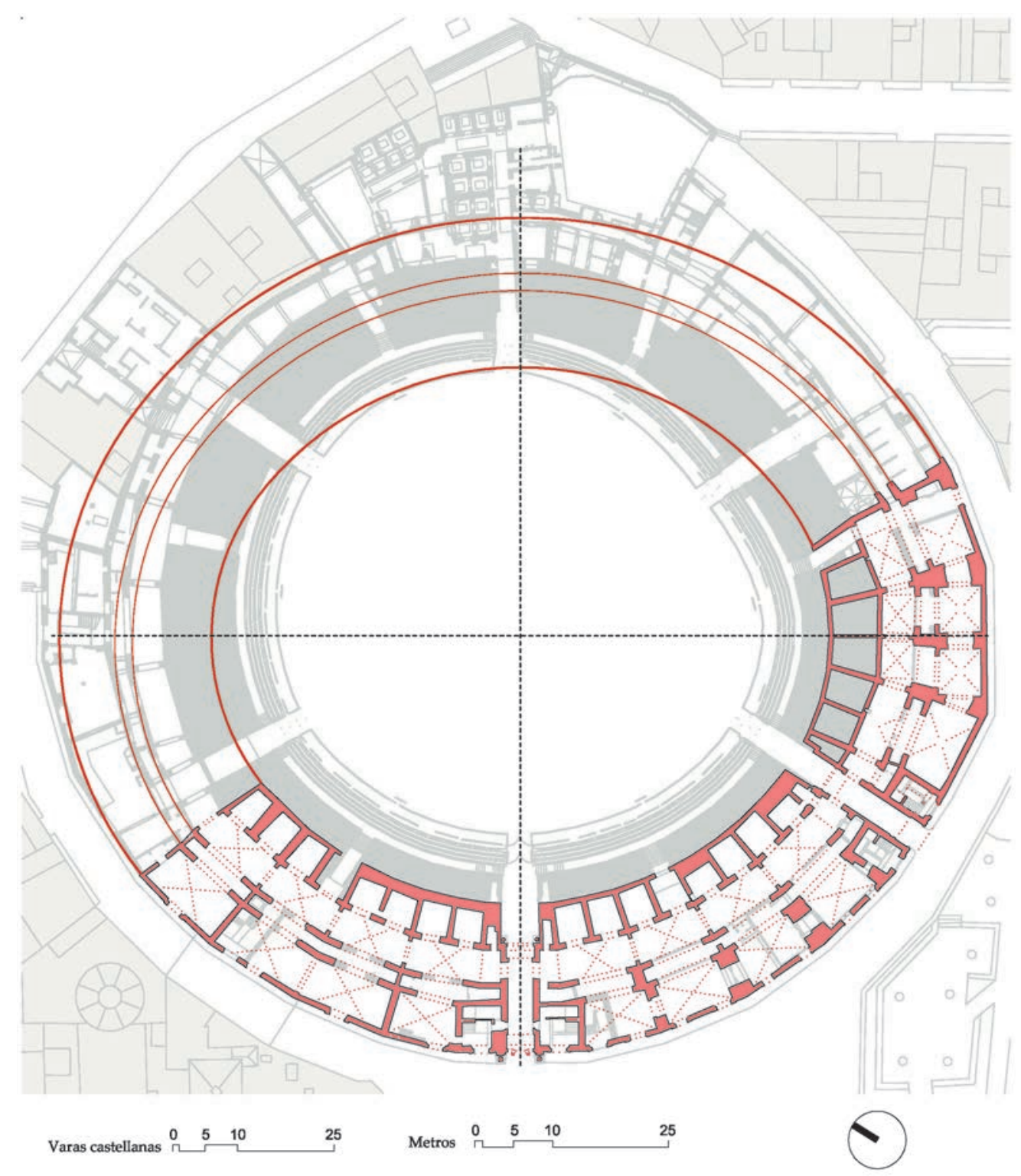

Figura 9. Recreación del Óvalo sobre Planta Actual. (Dibujo de los autores) 


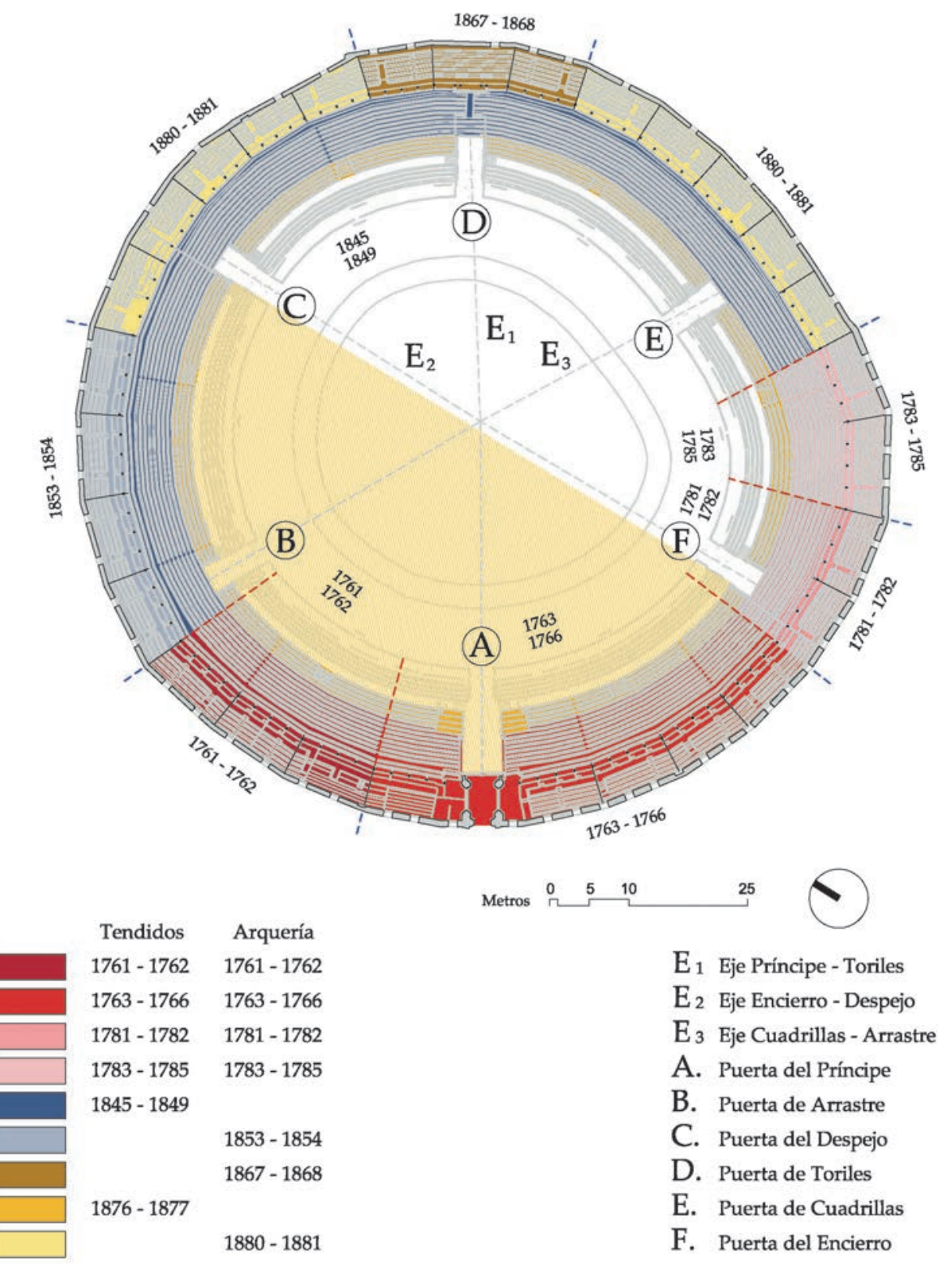

Figura 10. Períodos de Construcción hasta 1881. (Dibujo de los autores)

precisa, de cada una de ellas, con el fin de establecer la base geométrica sobre la que se habrían iniciado cada una de las sucesivas fases. De este modo ha sido posible reconstruir un proceso lógico y racional de determinación de centros, ejes y radios que dieran coherencia y verosimilitud a la traza actual que presenta la Plaza.

Antes de iniciar la descripción de este proceso debemos precisar que las líneas de barrera, contrabarrera y tendidos que presenta actualmente la Plaza responden a los proyectos y obras de José Sáenz y López y Aníbal González realizados entre 1913 y 1915 que vinieron a reducir considerablemente las dimensiones de un ruedo, que previamente ya había sido reducido por Juan Talavera de la Vega entre 1876 y 1877 al construir una plataforma para asientos de barrera. Un plano perteneciente al proyecto de Sáenz y López representando la sección de los tendidos (Figura 11), conservado en el archivo de la Corporación, junto con las prospecciones realizadas durante las obras de restitución de la Puerta del Despejo (10) permitieron definir la situación de la línea de contrabarrera primitiva, que viene prácticamente a coincidir con la fila sexta de los actuales tendidos. Una línea ésta que, en el caso de las tres primeras ochavas levantadas en fábrica, sería concéntrica con la barrera de la última de las plazas de madera, cuyo diámetro, como hemos apuntado anteriormente, alcanzaba las ochenta y dos varas castellanas. $(82 \mathrm{vc}=68,54 \mathrm{~m})$

Planteada la dimensión original del ruedo podemos grafiar sobre el plano actual de la Plaza estas tres primeras ochavas, levantadas entre 1761-1762, que corresponderían con las que actualmente definen los balcones impares 11 al 33 (Figura 12).

Estas ochavas, si bien comparten el mismo sistema constructivo que las que fueron levantadas entre 1763 y 1766, durante la segunda fase de obras (arcos impares 1 al 9, Balcón del 


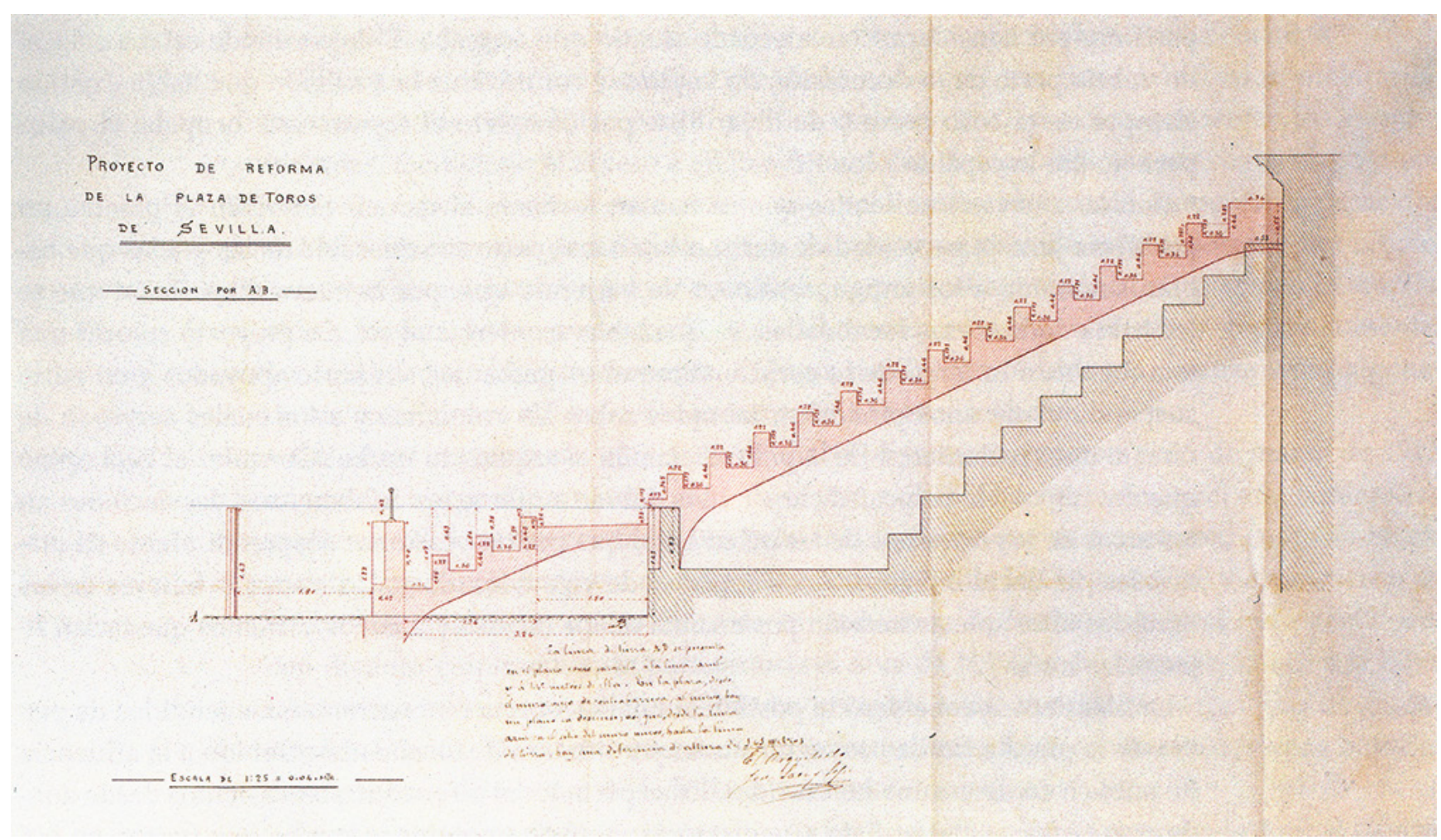

Figura 11. Sección del Proyecto de Reforma de la Plaza 1912. Sáez y López. Archivo Real Maestranza de caballería de Sevilla.

Príncipe, y arcos pares 2 al 36), presentan, sobre los capiteles y columnas de la arquería, pulvinos o ábacos ejecutados en fábrica de ladrillo, mientras que los de la segunda fase son de piedra caliza. De forma análoga en el comienzo de la tercera fase, ábacos y capiteles constituyen una sola pieza también labrada en piedra caliza.

La ejecución de la Puerta del Príncipe, flanqueada a ambos lados por sendas terrazas, impondría para la segunda fase de obras, la definición de un nuevo eje de simetría y de un nuevo centro para el arco de circunferencia que completarían las seis ochavas y un cuarto que habrían de levantarse. En este punto la traza de la plaza presentaría, como elementos fijos de la estructura geométrica, un centro $\mathrm{C}_{\mathrm{M}}$ correspondiente a la plaza de madera y un nuevo eje principal $\mathrm{E}_{1}$, definido por la Puerta del Principie.

Sobre este nuevo eje $\mathrm{E}_{1}$ se establecerá un también nuevo centro $\mathrm{C}_{1}$ que habría de comprender tanto las ochavas ejecutadas como las que se pretendían levantar. Este nuevo centro se obtendrá de la proyección del centro de la plaza de madera $\mathrm{C}_{\mathrm{M}}$ sobre el nuevo eje $\mathrm{E}_{1}$ siguiendo la dirección de la bisectriz del arco de ochavas ejecutadas. Una vez obtenidos el nuevo centro y el nuevo eje vertical, podemos definir el eje horizontal o mayor del óvalo $\mathrm{E}_{2}$ como la proyección perpendicular del centro de la plaza de madera $\mathrm{C}_{\mathrm{M}}$ sobre el eje $\mathrm{E}_{1}$ (Figura 13).

Esta estructura de ejes permite obtener igualmente de forma sencilla el segundo centro de un óvalo $\mathrm{C}_{2}$ como la intersección del radio trazado desde $\mathrm{C}$ hasta el extremo de la obra construida ( $1^{\mathrm{a}} \mathrm{y}^{\mathrm{a}}$ Fase) con el eje horizontal $\mathrm{E}_{2}$.

Así las ochavas levantas por Vicente de San Martín entre 1781-1785 serían trazadas tomando como referencia este nuevo centro $\mathrm{C}_{2} \mathrm{y}$ por tanto responderían a un plano de una Plaza de veintiocho ochavas y seis puertas, perfectamente ovalada y cuyos ejes alcanzarían ochenta y tres, y noventa y cinco varas respectivamente, y no a la traza contenida en el plano de Simancas que, en un intento por conformar una plaza circular, responde a la superposición de dos arcos de circunferencia cuyos centros se encuentran en $\mathrm{C}_{1} \mathrm{yC}_{0}$ siendo este último el punto de intersección de los dos ejes del óvalo (Figura 14).

La hipótesis de un plano de planta ovalada (Figuras 8 y 15) que hubiera servido de base a las obras realizadas en estas tres fases parece quedar corroborada, no sólo por un procedimiento geométrico tan evidente como el descrito, sino también por la traza diversa que presenta la ochava que vendría a coincidir con el eje horizontal o mayor $\mathrm{E}_{2}$ del óvalo, ejecutada con dos bóvedas de arista, simétricas respecto a este eje, en lugar de una prolongada en cañón como presentan todas las anteriores, así como también por la disposición de las fábricas en el punto en el que concluyen las obras de Vicente de San Martín, que vienen a coincidir con la posición que habría de ocupar la torre-escalera que flanquearía la Puerta de Picadores, simétrica de la del Encierro respecto al eje horizontal del óvalo.

Entre 1845 y 1849 Juan Manuel Caballero cerraría el ruedo, olvidando ya la figura regular del óvalo para intentar asimilarla a una forma próxima al círculo. El trazado de este último sector de Plaza se realizará mediante tres arcos de circunferencia cuyos centros se determinarán, como no podía ser de otra forma, tomando como base reguladora las obras ya ejecutadas. Así Juan Manuel Caballero debió tomar como referencia los ejes vertical y horizontal del óvalo $\mathrm{E}_{1}$ y $\mathrm{E}_{2} \mathrm{y}$ un tercer eje, el definido por la Puerta del Encierro, coincidente con el Eje de división entre Sol y Sombra (Figura 16-A). 

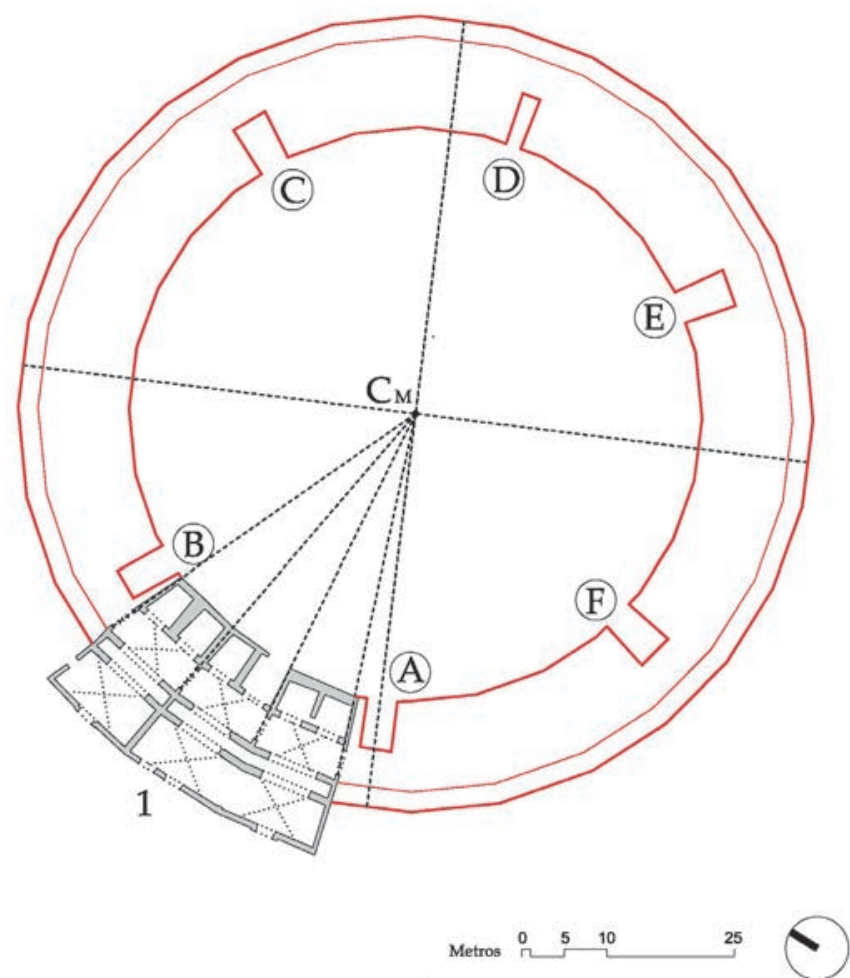
1. Primeras Tres Ochavas Edificadas en Fábrica
A. Puerta del Príncipe
D. Puerta de Toriles
$\mathrm{C}_{\mathrm{M}}$ Centro de la Plaza de Madera
B. Puerta de Toros Muertos E. Puerta de Picadores
C. Puerta de la Tropa
F. Puerta del Encierro

Figura 12. $1^{\text {a }}$ Fase de la Obra de Fábrica sobre la Plaza de Madera. 1761-1762. (Dibujo de los autores)

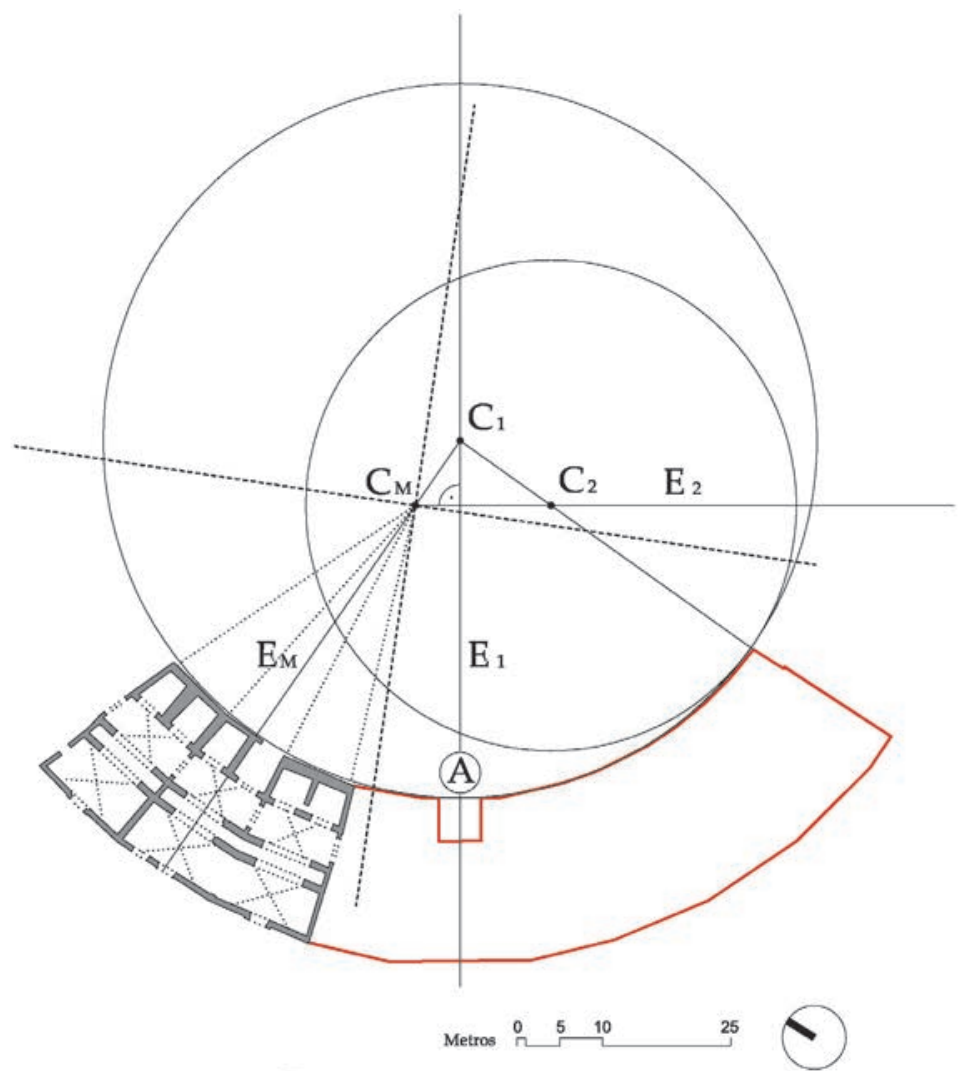

$\mathrm{C}_{\mathrm{M}}$ Centro de la Plaza de Madera

E M Bisectriz de las Ochavas Levantadas A. Puerta del Príncipe

$\mathrm{C}_{1}$ Centro de la Nueva Fase de Obras $\mathrm{E}_{1}$ Nuevo Eje Vertical. Puerta del Príncipe

$\mathrm{C}_{2}$ Segundo Centro del Óvalo $\quad \mathrm{E}_{2}$ Nuevo Eje Horizontal del Óvalo

Figura 13. Centro y Nuevos Ejes de la $2^{\text {a }}$ Fase de la Obra de Fábrica. 1763-1766. (Dibujo de los autores) 


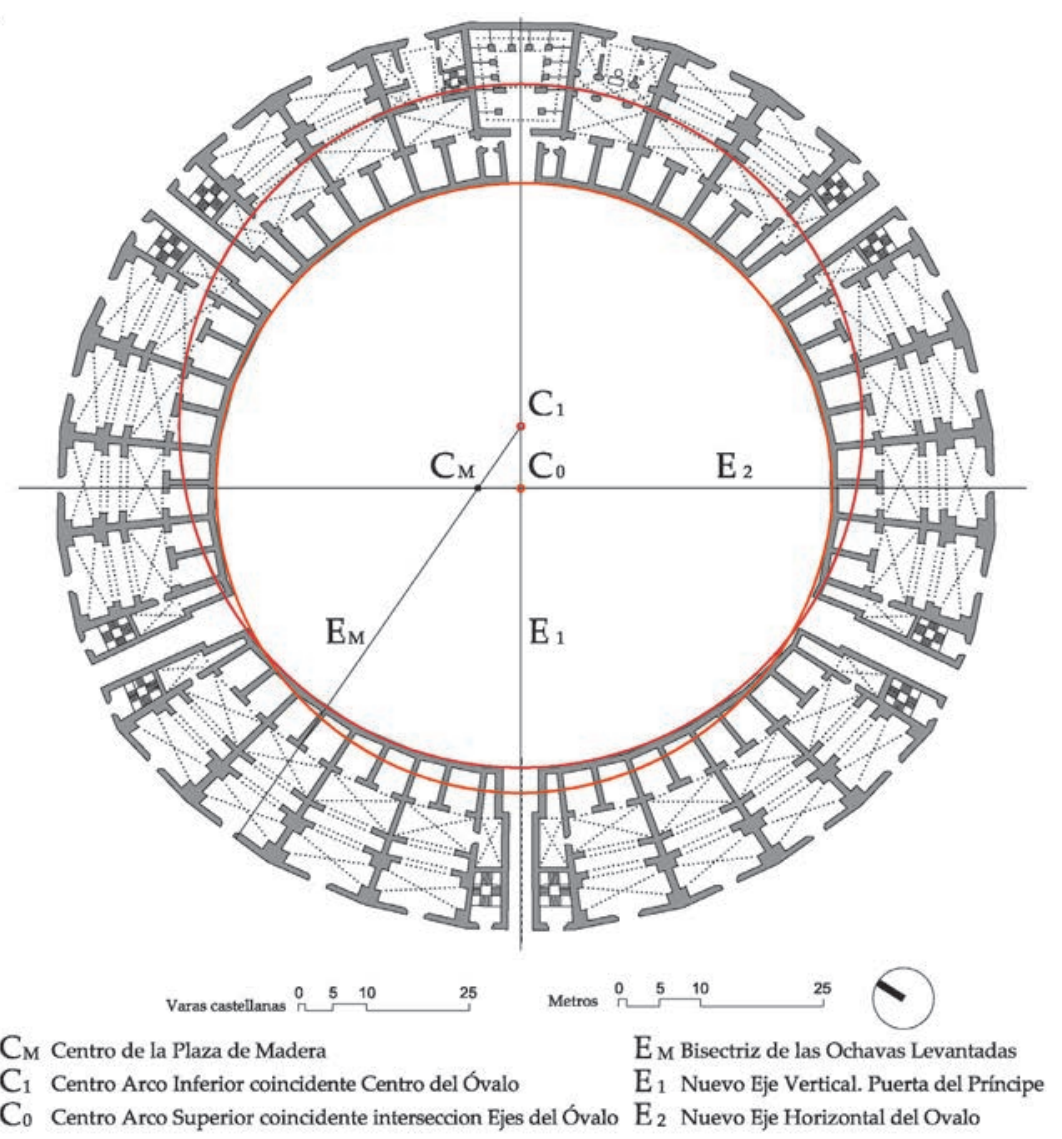

Figura 14. Centros del plano de Simancas - Vinculados con los centros y ejes del Óvalo. (Dibujo de los autores)

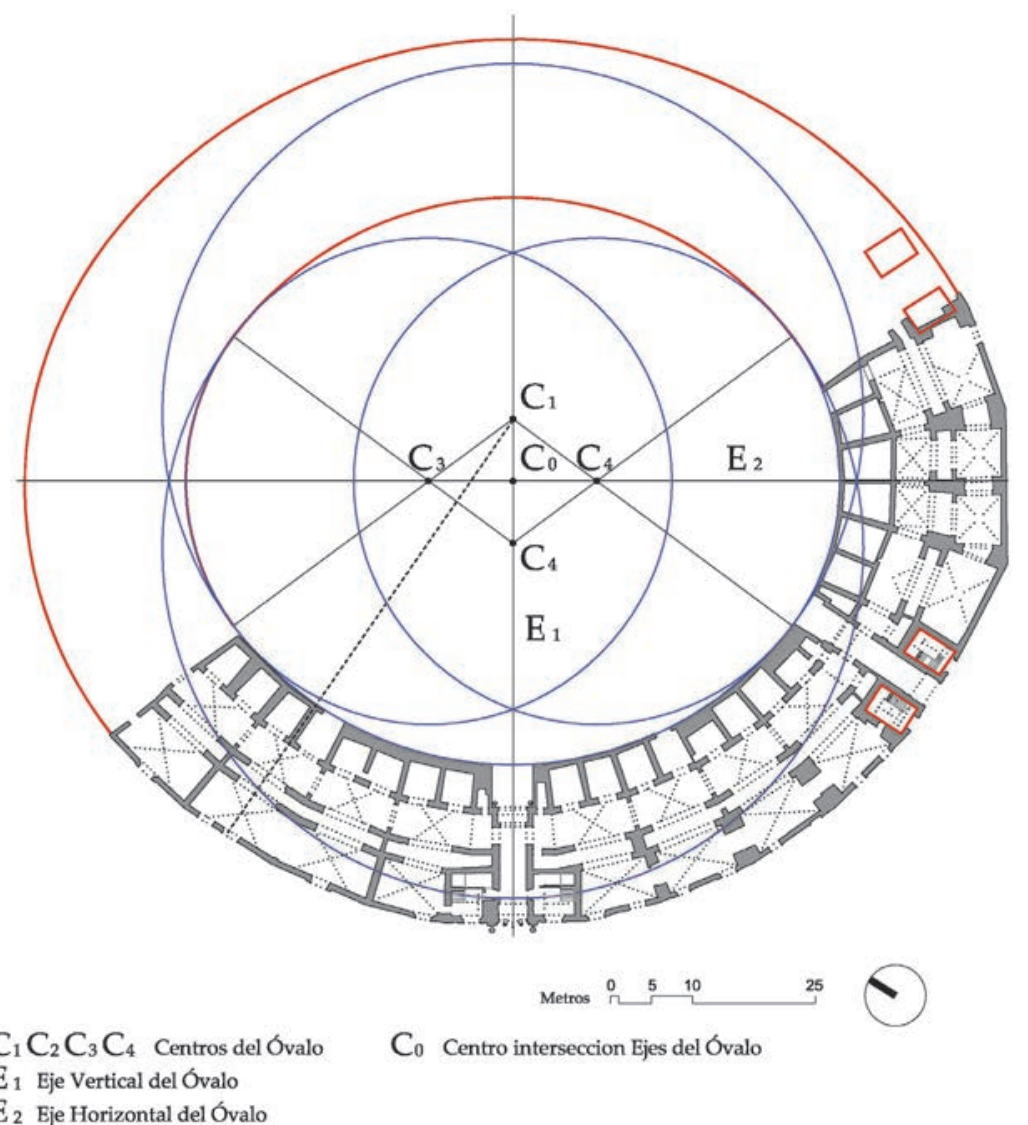

Figura 15. Traza del Óvalo correspondientes a las Obras de la $3^{\text {a }}$ Fase. 1781-1785. (Dibujo de los autores) 


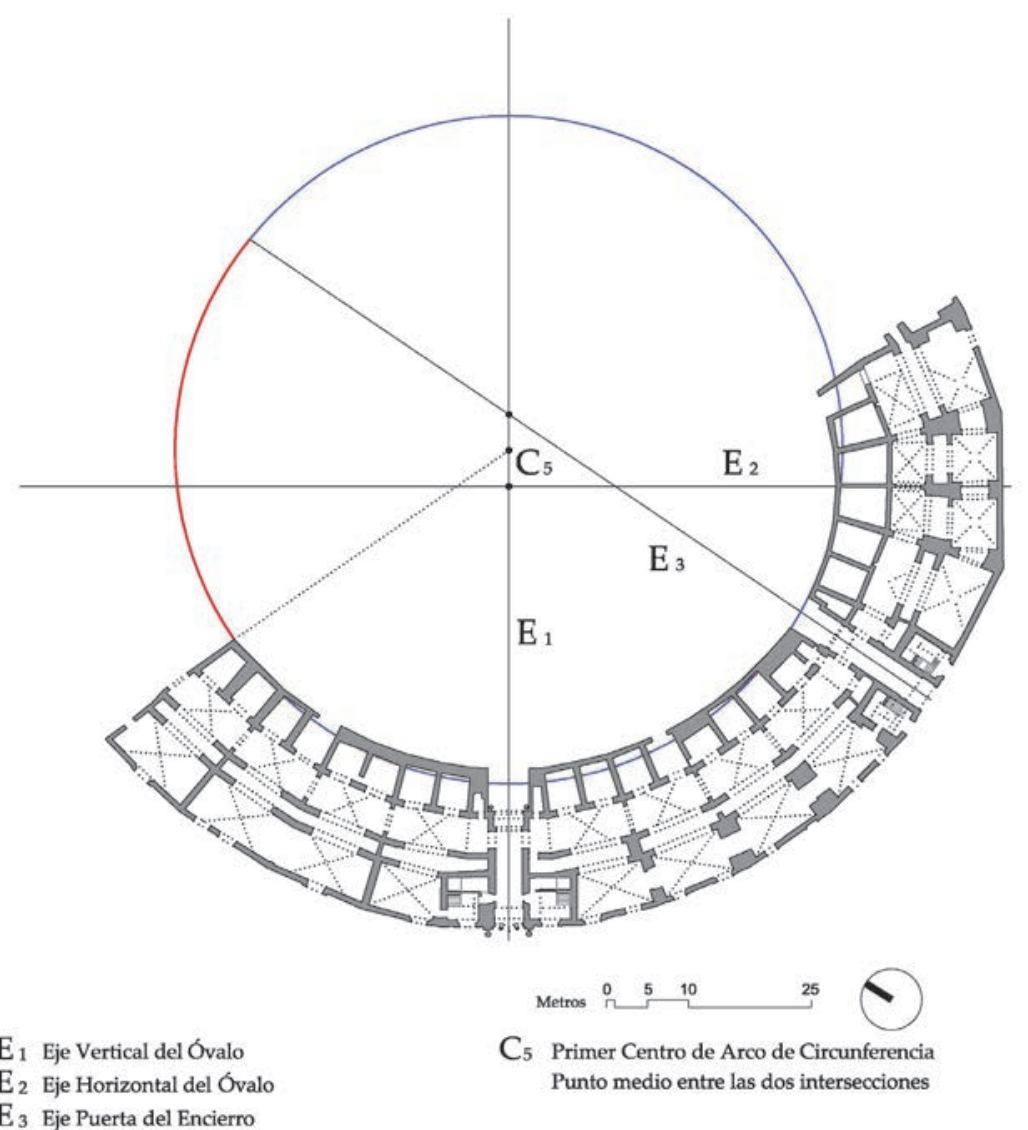

Figura 16-A. Trazado del Primer Arco de Circunferencia del cierre de la Plaza. (Dibujo de los autores)

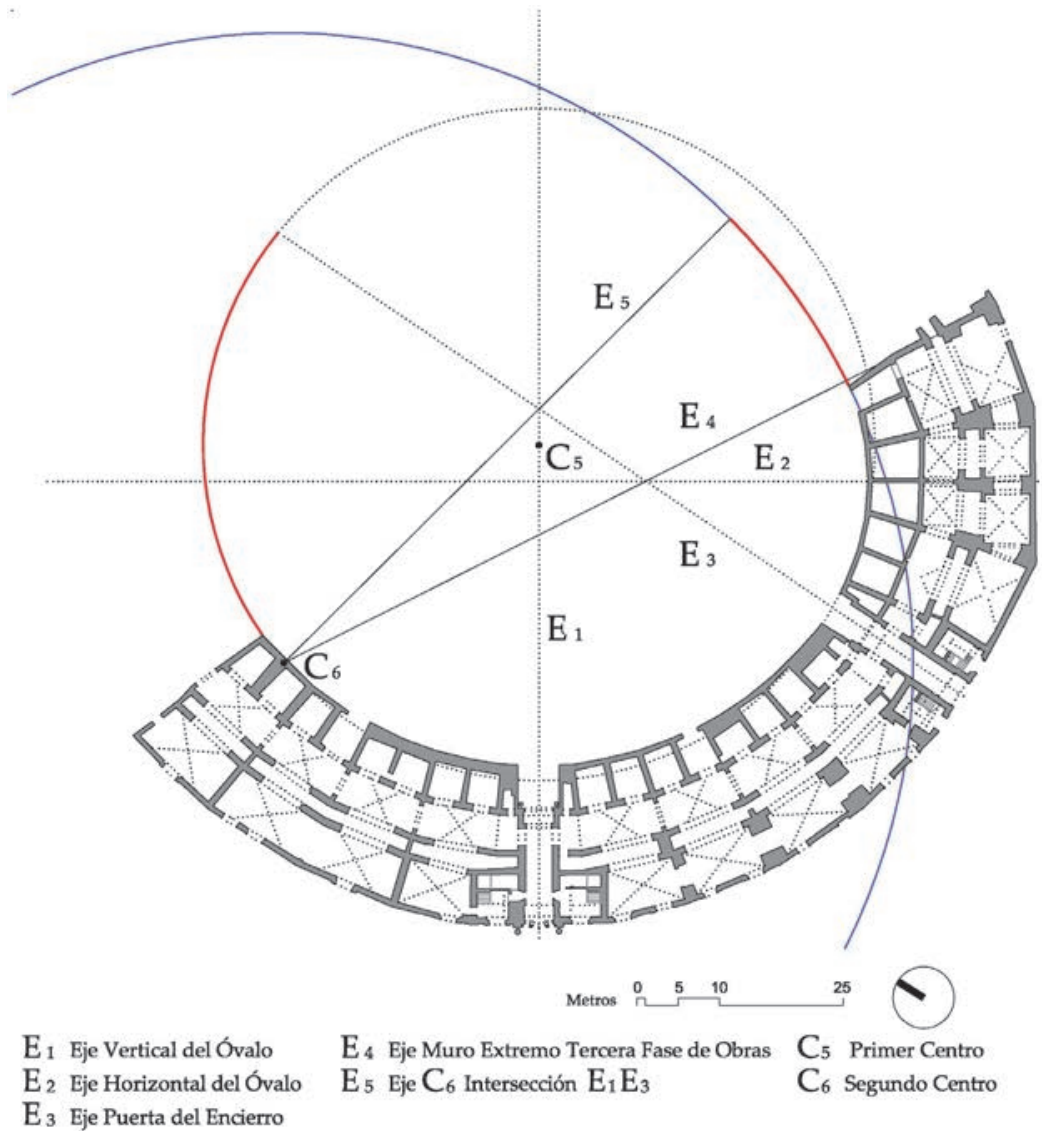

Figura 16-B. Trazado del Segundo Arco de Circunferencia del cierre de la Plaza. (Dibujo de los autores) 


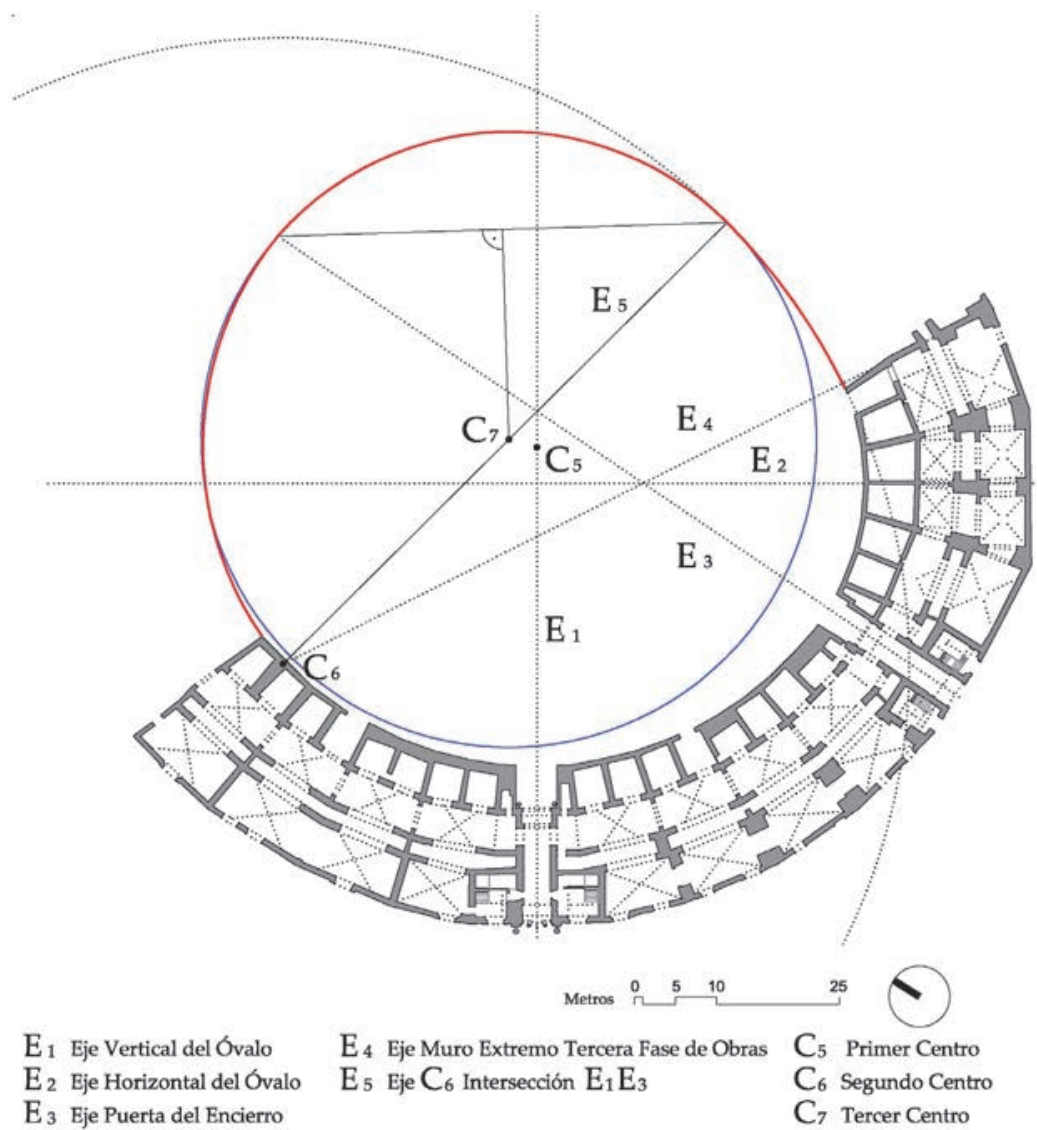

Figura 16-C. Trazado del Tercer Arco de Circunferencia del cierre de la Plaza. (Dibujo de los autores)
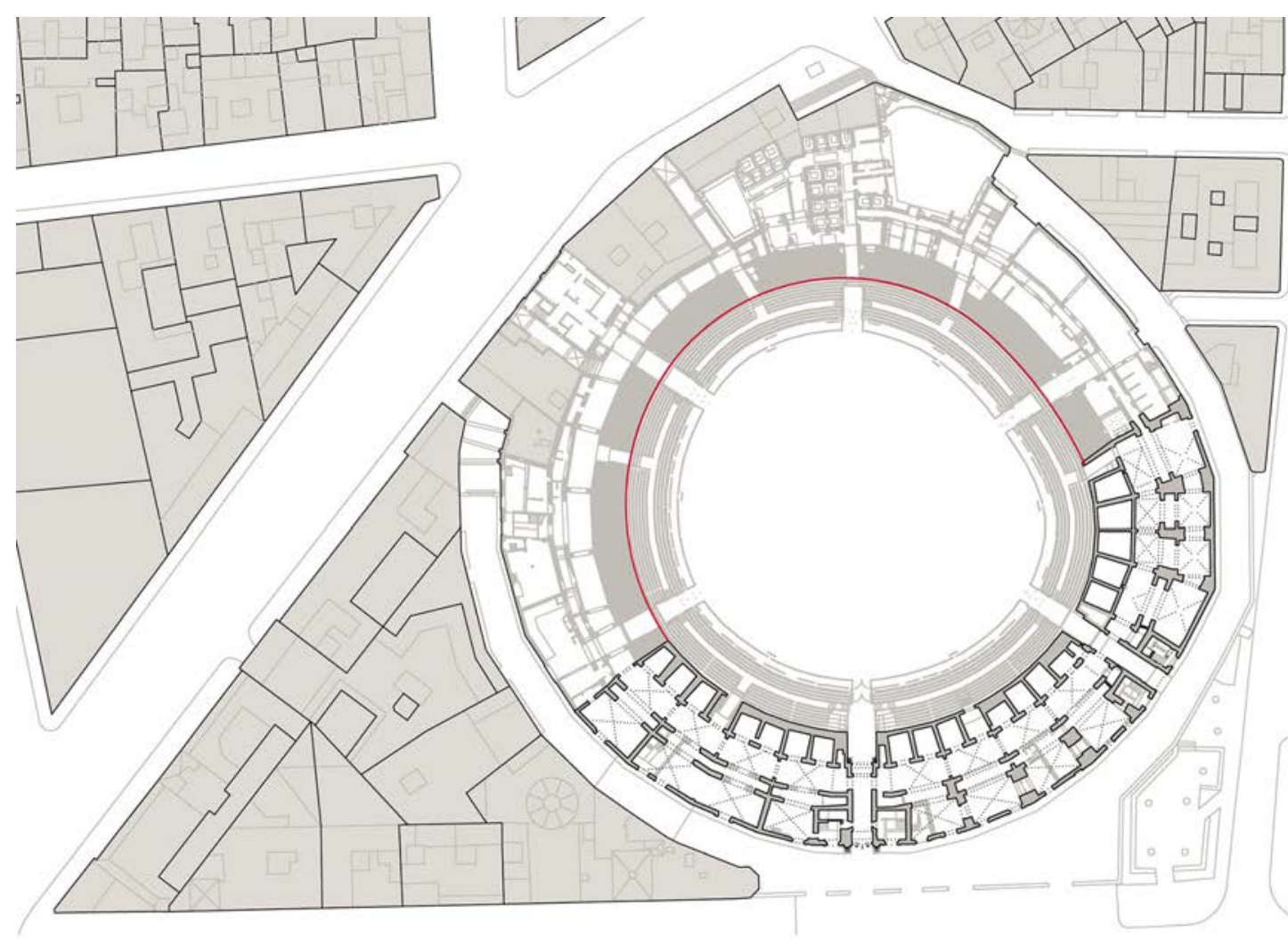

Metors $\stackrel{0}{2}-10$
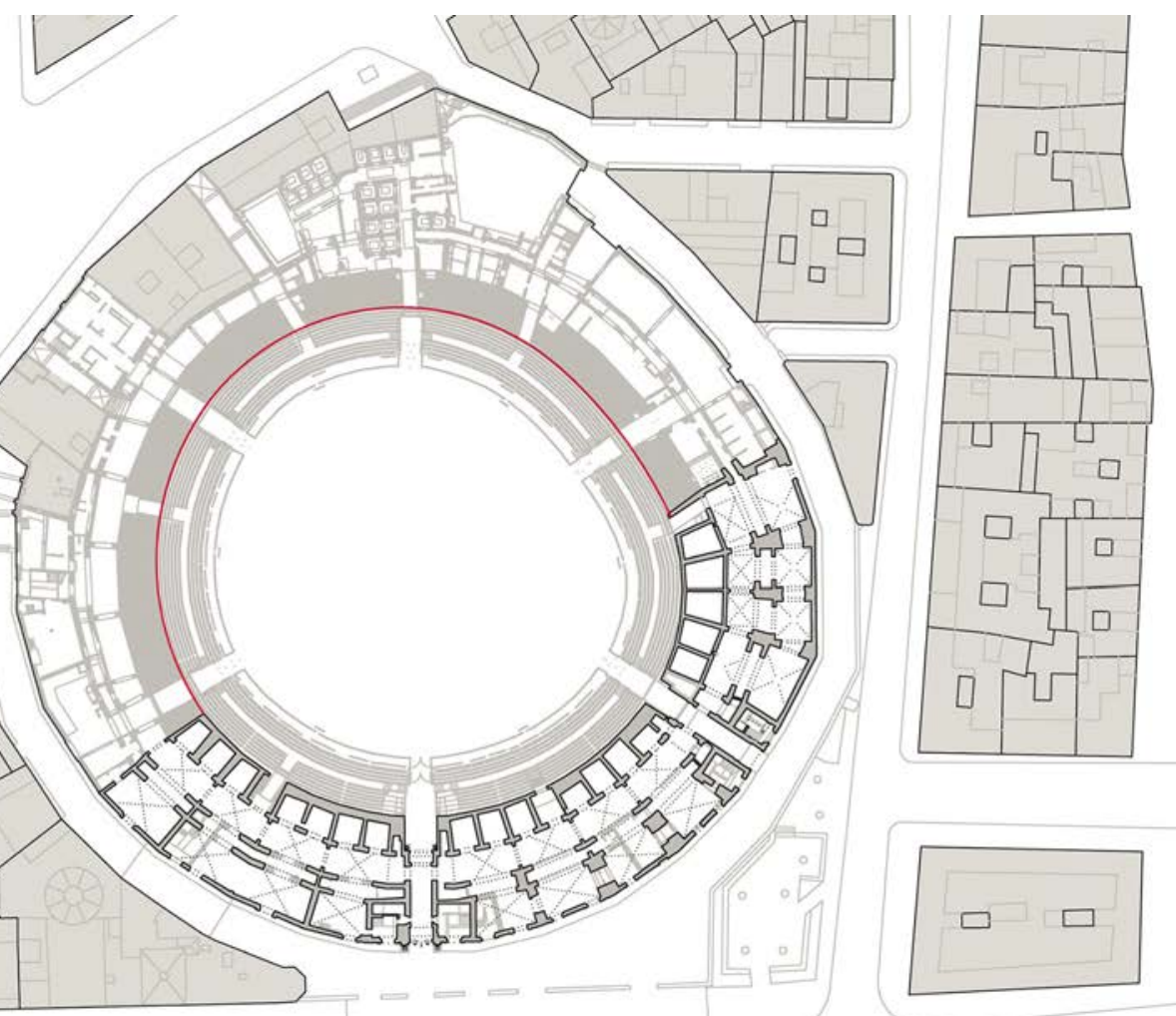

Figura 17. Superposición de la Traza sobre la Planta Actual de la Plaza. Escala 1/500. (Dibujo de los autores) 
El primero de los centros $\mathrm{C}_{5}$ se obtendría como punto medio de la distancia entre el punto de intersección del Eje Sol y Sombra $\left(\mathrm{E}_{3}\right)$ con el Eje Vertical ( $\left.\mathrm{E}_{1}\right)$, y el punto de intersección entre los ejes mayor y menor del óvalo. Este nuevo centro permitiría trazar un arco en el sentido de las agujas del reloj como continuación de las fábricas levantadas en la primera fase de obras.

El eje del muro extremo de las ochavas levantadas en la tercera fase, prolongado hasta cortar con la circunferencia trazada con centro en $\mathrm{C}_{5}$, determinaría un segundo centro $\mathrm{C}_{6}$ que permitiría dibujar el arco que prolongaría las fábricas en este sector, ahora en sentido contrario al de las agujas del reloj (Figura 16-B).
Finalmente el tercer centro $\mathrm{C}_{7}$ se obtendría como el de aquella circunferencia que, pasando por los dos puntos extremos de los arcos anteriores, resultara tangente al segundo de estos. (Figuras 16-C y 17) Una vez obtenido este trazado geométrico del cierre del ruedo, Caballero pudo proceder por fases a la sustitución de los andamios de madera por los nuevos tendidos de fábrica.

A modo de resumen podríamos decir que la Plaza de la Maestranza en ese debate entre circular y ovalada, nació circular, la Ilustración la pretendió ovalada y finalmente, en un esfuerzo surgido de su propia tradición, intentó volver al círculo.

\section{REFERENCIAS}

(1) Halcón, F. (1990). La Plaza de Toros de la Real Maestranza de Sevilla. p.71. Madrid: Ediciones el Viso.

(2) Gómez de Terreros, M. a V. (1999). Plaza de Toros de la Real Maestranza de Sevilla. Historia de su Construcción. p. 62. Huelva: Fundación El Monte / Universidad de Huelva.

(3) Halcón, F. (1990) La Plaza de Toros de la Real Maestranza de Sevilla. p.81. Madrid: Ediciones el Viso.

(4) Gómez de Terreros, M. ${ }^{a}$ V. (1999). Plaza de Toros de la Real Maestranza de Sevilla. Historia de su Construcción. pp. 6667. Huelva: Fundación El Monte / Universidad de Huelva.

(5) Gómez de Terreros, M. ${ }^{a}$ V. (1999). Plaza de Toros de la Real Maestranza de Sevilla. Historia de su Construcción. p. 70. Huelva: Fundación El Monte / Universidad de Huelva.

(6) Romero de Solís, P. (2003). La Invención de la Plaza de Toros de Sevilla. En Historia Gráfica de la Plaza de Toros de Sevilla. (pp. 77-109) Sevilla: Real Maestranza de Caballería de Sevilla.

(7) Gómez de Terreros, M. ${ }^{a}$ V. (1999). Plaza de Toros de la Real Maestranza de Sevilla. Historia de su Construcción. pp. 7680. Huelva: Fundación El Monte / Universidad de Huelva.

(8) Gómez de Terreros, M. a V. (1999). Plaza de Toros de la Real Maestranza de Sevilla. Historia de su Construcción. p. 77. Huelva: Fundación El Monte / Universidad de Huelva.

(9) Gómez de Terreros, M. ${ }^{a}$ V. (1999). Plaza de Toros de la Real Maestranza de Sevilla. Historia de su Construcción. p. 81. Huelva: Fundación El Monte / Universidad de Huelva.

(10) Carbajal, J.A. (2011). El Eje Puerta del Encierro Puerta del Despejo. En Plaza de Toros de la Real Maestranza de Caballería de Sevilla. Obras 2005-2011 (pp. 67-109). Sevilla: Real Maestranza de Caballería de Sevilla. 